\title{
Electrochemical and pitting corrosion resistance of AISI 4145 steel subjected to massive laser shock peening treatment with different coverage layers
}

\author{
J.Z. Lu ${ }^{1}$, B. $\mathrm{Han}^{1}$, C.Y. Cui ${ }^{1}$, C.J. Li ${ }^{2}$, K.Y. Luo ${ }^{1}$ \\ ${ }^{I}$ School of Mechanical Engineering, Jiangsu University, Zhenjiang, 212013, PR China \\ ${ }^{2}$ School of Energy and Power Engineering, Jiangsu University, Zhenjiang, 212013, PR China
}

\begin{abstract}
The effects of massive laser shock peening (LSP) treatment with different coverage layers on residual stress, pitting morphologies in a standard corrosive solution and electrochemical corrosion resistance of AISI 4145 steel were investigated by pitting corrosion test, potentiodynamic polarisation test, and SEM observations. Results showed massive LSP treatment can effectively cause an obvious improvement of pitting corrosion resistance of AISI 4145 steel, and increased coverage layer can also gradually improve its corrosion resistance. Massive LSP treatment with multiple layers was shown to influence pitting corrosion behaviour in a standard corrosive solution.
\end{abstract}

Keywords: Carbon steel; SEM observation; Polarisation; Electrochemical calculation; Pitting corrosion

\footnotetext{
Corresponding author: Xuefu Road 301, Jingkou District, Zhenjiang 212013, PR China Email address: jzlu@mail.ujs.edu.cn, blueesky2005@163.com (J.Z. Lu)

Tel.: +86-511-88797198; Fax: +86-511-88780219
} 


\section{Introduction}

AISI 4145 steel is widely used in $\mathrm{Y}$-connectors of petroleum pipelines at an elevated temperature of $250{ }^{\circ} \mathrm{C}$ because of its excellent properties. To meet the design requirement of these connectors, improvement of the steel strength, wear and corrosion resistance through surface treatment technology is essential. Laser shock peening (LSP) is an effective way to improve the surface hardness, fatigue performance, corrosion resistance and wear resistance of metallic materials through generation of a deeper surface layer of refined grains and compressive residual stresses in the metallic material surface $[1,2]$.

Over the last decade, substantial research efforts have yielded significant insights into the effects of LSP on the corrosion resistance of metallic materials [3-6, 7]. For example, Trdan et al. $[3,4]$ recently examined the effects of LSP without coating on the corrosion behaviour of AA6082-T651 alloy in a near-neutral chloride environment, and results confirmed that LSP without coating reduces crystallographic and surface-hemispherical pitting and intergranular attacks. The corrosion potential of a material is enhanced when its corrosion current density increases with increasing laser pulse density [5]. Telang et al. [6] recently presented enhancements in the stress corrosion cracking (SCC) behaviour of nickel-based Alloy 600 in tetrathionate solution and found that SCC susceptibility decreases after LSP treatment. The corrosion behaviour of AA2050-T8 was studied after polishing and after LSP treatment using the electrochemical microcell technique and the SVET, and the results revealed that LSP increases the pitting potential, and the current density on the LSP-treated surface remains constant around $50 \mu \mathrm{A} \mathrm{cm} \mathrm{cm}^{-2}$ as compared to the polished surface reaches $200 \mu \mathrm{A} \mathrm{cm}^{-2}$ [7]. Steels are alloys of iron, primarily 
carbon and other elements, and widely used in construction and other applications because of their high tensile strength and low cost. LSP to improve steel corrosion resistance has been extensively studied in the literature. Jeong et al. reported that the corrosion rate of 2205 duplex stainless steel is reduced by $74.2 \%$ and that the number density and diameter of corrosion pits decrease to less than half the original values when LSP is applied [8]. Peyre et al. demonstrated that LSP results in better pitting corrosion resistance of $316 \mathrm{~L}$ steel in $0.5 \mathrm{M} \mathrm{NaCl}$ solution [9] and effectively prevents SCC crack initiation in boiling $\mathrm{MgCl}_{2}$ solution [10]. Kalainathan et al. revealed that the corrosion current density of 316L steel increases with increasing laser pulse density during LSP without coating, and an enhancement in corrosion potential was also observed [11]. In our previous work, we investigated the effects of LSP on the SCC susceptibility and electrochemical corrosion resistance of AISI 304 steel and found that LSP effectively causes obvious improvements in ultimate tensile strength, SCC resistance and electrochemical corrosion resistance $[12,13]$. These improvements may be attributed to LSP-induced compressive residual stresses, increased yield strength and grain refinement in the near-surface layer of the steel. Similar results can also be obtained in the influence of shot peening and ultrasonic peening on the corrosion properties of AISI 304 stainless steel [14].

In fact, for the carbon steel, conventional mechanical treatments, such as shot peening, exerts crucial effects on intergranular corrosion by desensitising welded assemblies through coarse grain refinement [9]. The ratio of ferrite to pearlite and their distribution in carbon steel are important factors influencing the corrosion resistance of carbon steel. However, few related reports describing the effects of LSP on the microstructural distribution of carbon steel have been published. In addition, research on the mechanism of the effects of massive LSP treatment on the 
corrosion resistance of carbon steel is relatively limited.

The present study aims to investigate the effects of LSP on the pitting morphology and electrochemical corrosion resistance of AISI 4145 medium carbon steel in a standard corrosive solution containing chloride ions. The effect of number of coverage layers during massive LSP treatment on the residual stress distribution, electrochemical corrosion performance and pitting morphology of AISI 4145 steel is emphasised in this study. In particular, the ratio of ferrite to pearlite and their distributions before and after massive LSP treatment are compared and analysed. Finally, the influence mechanism of massive LSP treatment with coverage layers on the corrosion resistance of AISI 4145 steel is revealed.

\section{Experimental procedures}

\subsection{Material and specimen preparation}

The substrate material used in the experiment was AISI 4145 medium carbon steel. All of the specimens were cut and machined from a steel plate with a thickness of $2 \mathrm{~mm}$. The chemical composition of AISI 4145 steel is $0.75 \mathrm{Mn}, 0.006 \mathrm{P}, 0.008 \mathrm{~S}, 0.26 \mathrm{Si}, 0.85 \mathrm{Cr}, 0.45 \mathrm{C}, 0.16 \mathrm{Mo}$, and balance $\mathrm{Fe}(\mathrm{wt} . \%)$, and its mechanical properties are listed in Table 1.

Two types of plane specimens were prepared for our corrosion resistance and electrochemical corrosion behaviour studies at elevated temperature, and the dimensions and images of these specimens are shown in Fig. 1. The first specimen (Fig. 1a) was machined to dimensions of 40 $\mathrm{mm}$ (length) $\times 13 \mathrm{~mm}($ width $)$, and a rectangular region with dimensions of $13 \mathrm{~mm}$ (length) $\times 13$ $\mathrm{mm}$ (width) in the center of the specimen was obtained by massive LSP treatment. A hole with a diameter of $8 \mathrm{~mm}$ was used to hang the specimen during the corrosion experiment at an elevated temperature of $250^{\circ} \mathrm{C}$. The second specimen was machined to dimensions of $25 \mathrm{~mm}$ (length) $\times 10$ 
$\mathrm{mm}$ (width), and a rectangular region with dimensions of $10 \mathrm{~mm}$ (length) $\times 10 \mathrm{~mm}$ (width) was obtained by LSP treatment for the electrochemical corrosion test (Fig. 1b). Prior to LSP, all specimens were progressively mechanically polished to achieve smooth surfaces and subsequently cleaned with acetone and subjected to ultrasonic vibration to degrease their surfaces

\subsection{Massive LSP treatment}

Massive LSP treatment was conducted using a Q-switched Nd: YAG (GAIA-R, THALES) laser system operating at $1064 \mathrm{~nm}$ with a top-hat pulse width of $10 \mathrm{~ns}, 1 \mathrm{~Hz}$ repetition-rate and laser spot diameter of $3 \mathrm{~mm}$. In the present work, two pulse energies, i.e., $4 \mathrm{~J}$ and $8 \mathrm{~J}$, were chosen. The absorption and transparent confinement layers, and the overlapping rate between two adjacent round spots in the transverse perpendicular and parallel directions can be presented in the literature [15]. As shown in Fig. 1, one coverage layer is defined as the point where the grey region is completely covered by one cycle of massive LSP treatment. If a second coverage layer was necessary after LSP treatment of the grey region, the absorption layer must be replaced and the first step must be repeated. In the present study, we defined this process as 'two coverage layers'. Subsequent steps were denoted according to this rule. Three types of LSP-treated (LSPed) specimens were used in the present work. The first type of LSPed specimen is that the as-machined specimen is treated by one coverage layer with a pulse energy of $4 \mathrm{~J}$, the second type of LSPed specimen is that the as-machined specimen is treated by one coverage layer with a pulse energy of $8 \mathrm{~J}$, and the third type of LSPed specimen is that the as-machined specimen is treated by two coverage layers with a pulse energy of $8 \mathrm{~J}$. Due to the LSPed region is obviously larger than the laser spot, the above-mentioned LSPed need to be treated by massive LSP treatment [16]. During massive LSP treatment, the overlapping rate between two adjacent round spots was $50 \%$ in 
both transverse and longitudinal directions to ensure that no blind area existed at the LSPed region.

\subsection{Residual stress measurement}

XRD tests were performed using the $\sin ^{2} \psi$ method to characterise the surface and in-depth residual stresses of the steel specimens. The scanning start and termination angles were $160^{\circ}$ and $150^{\circ}$, respectively, and the diffraction plane was the $\beta$ phase (211) plane. The other parameters can be found in the previous publication [11]. Measurements were repeated thrice for each point, and the average value was obtained and recorded. The electrolytic polishing material removal method was used to measure in-depth residual stress. The top $100 \mu \mathrm{m}$ surface layer of the AISI 4145 steel was polished layer by layer with an 87.5: 12.5 vol. $\% \mathrm{CH}_{3} \mathrm{OH}: \mathrm{H}_{2} \mathrm{SO}_{4}$ electrolytic solution, and the thickness of every removed layer was measured by measuring the specimen thickness again using a precise micrometer.

\subsection{Corrosion experiment and electrochemical corrosion test}

As shown in Fig. 1a, the rectangular region with dimensions of $13 \mathrm{~mm}$ (length) $\times 13 \mathrm{~mm}$ (width) in the center on the specimen surface was treated by massive LSP treatment with one coverage layer and a pulse energy of $8 \mathrm{~J}$, we call this kind of specimen as the LSPed specimen. Subsequently, five LSPed specimens and five as-machined specimens were immersed in Therminol 72 solution at $250{ }^{\circ} \mathrm{C}$ for $72 \mathrm{~h}$, while other five LSPed specimens and five as-machined specimens were kept in the same solution for $200 \mathrm{~h}$. Therminol 72 solution is a mixture of synthetic aromatics, and its chemical composition was 220 ppm moisture, 200 ppm KOH, 10 ppm chlorine, and balance aromatics (wt.\%).

Twelve original rectangular steel plates (as shown in Fig. 1b) were used for the 
potentiodynamic polarisation test. Three of all original specimens were regarded as the as-machined specimens, and the other specimens were divided into three groups which were treated by 1, 2, and 3 coverage layers with a pulse energy of $8 \mathrm{~J}$, respectively. After massive LSP treatment, all specimens were cut as square specimens with a dimension of $13 \mathrm{~mm} \times 13 \mathrm{~mm}$ along the LSPed region in Fig. 1a.

To evaluate the effects of the number of coverage layer on the pitting corrosion resistance of AISI 4145 steel, all square specimens were immersed in $0.598 \mathrm{~mol} / \mathrm{L} \mathrm{NaCl}$ solution at room temperature. According to ASTM standard G5-94, potentiodynamic polarisation curves as a function of coverage layer were obtained. A saturated calomel electrode (SCE) was used as the reference electrode, and a platinum foil $(\mathrm{Pt})$ was used as the counter electrode. Three-electrode system used for the electrochemical test, as shown in the publication [17]. All specimens were mounted with epoxy resin on an electrode holder, and the potential scan rate applied for all potentiodynamic polarisation tests was $0.5 \mathrm{mV} / \mathrm{s}$. The applied potentials for potentiodynamic polarisation curve measurement varied from $-0.45 \mathrm{~V}$ (vs. SCE) to $-0.25 \mathrm{~V}$, and the current density during iodisation was recorded at $1 \mathrm{~s}$ intervals. Corrosion current densities were determined from polarisation curves using the Tafel extrapolation method. Electrochemical impedance spectroscopy (EIS) was performed on as-machined and LSPed specimens through a LK-2005A electrochemical workstation, and the impedance measurements were carried out at open circuit potential in the frequency range of $100 \mathrm{~Hz}$ to $10 \mathrm{kHz}$.

\subsection{Micro-structural observations}

Specimen surfaces used for metallographic investigation as a function of coverage layer were cut. Subsequently, these specimens were subjected to several successive steps of grinding and 
polishing, and then etched using a solution consisting of 4 vol.\% $\mathrm{HNO}_{3}$ and 96 vol.\% ethanol at room temperature. Finally, surface morphologies were observed by JSM-7001F scanning electron microscope (SEM). Surface morphologies and energy spectra of each specimen taken from the elevated temperature experiments were characterized. After the potentiodynamic polarisation test, all surface morphologies of the specimens were also observed.

\section{Results and Discussion}

\subsection{Pitting morphologies after pitting corrosion test at elevated temperature}

To investigate the effect of massive LSP treatment on the pitting corrosion performance of AISI 4145 steel at elevated temperature, the second LSPed specimen is selected as the LSPed specimen. The typical pitting morphologies of as-machined and LSPed specimens with one coverage layer and a pulse energy of $8 \mathrm{~J}$ exposed for $72 \mathrm{~h}$ and $200 \mathrm{~h}$ in Therminol 72 solution at $250{ }^{\circ} \mathrm{C}$ are presented in Figs. 2 and 3, respectively. In general, there is a linear relationship between the diameter of corrosion pit and the corresponding depth. In the literature [18], it can be found that in all cases the initial aspect ratio of one of the corrosion pits is kept a constant $\mathrm{D} / \mathrm{W}=0.1$. Where $\mathrm{L}$ is the initial distance between two adjacent pits, and $\mathrm{W}$ and $\mathrm{D}$ are the diameter and the depth of corrosion pit, respectively. Hence, a small pit diameter corresponds to smaller pit depth, which represents better pitting corrosion resistance. In the present work, only the diameter of corrosion pit measured and the depth of corrosion pit assumed according to a previously observed depth-to-width ratio.

Fig. 2 shows the typical pitting morphologies of the as-machined and LSPed specimens after pitting corrosion in Therminol 72 solution at $250{ }^{\circ} \mathrm{C}$ for $72 \mathrm{~h}$. Figs. $2 \mathrm{a}-2 \mathrm{~d}$ reveal the typical pitting morphology of the as-machined specimen. Fig. 2a shows numerous corrosion pits with an average 
diameter of about $10-40 \mu \mathrm{m}$ on the as-machined specimen surface. Most of these corrosion pits grow independently without interaction with other pits. A single large pit is formed in Therminol 72 solution, as presented in Fig. 2b. The large pit is fairly deep, a hole with a diameter of $20 \mu \mathrm{m}$ may be found in the center of this pit, and a spalling layer may be observed around the hole, as marked in the inset of Fig. $2 b$ and Fig. $2 d$. These results reveal that small holes are formed before the formation of large pits. Massive corrosion spalling and micro-cracks can also be observed on the as-machined specimen surface, as shown in Ellipse B in Figs. 2c and 2d, respectively.

Figs. 2e-2h show the typical pitting morphologies of LSPed specimens with one coverage layer and a pulse energy of $8 \mathrm{~J}$ at different magnification levels. Compared with the corrosion pit of the as-machined specimen, the corrosion pits of the LSPed specimen surface are small and uniform with an average diameter of about 2-5 $\mu \mathrm{m}$, as shown in Fig. 2e. A typical corrosion pit obtained after massive LSP treatment can be seen in Fig. $2 \mathrm{f}$, and several corrosion holes with diameters less than $1 \mu \mathrm{m}$ are found in this corrosion pit. Numerous corrosion holes with diameters of less than $1 \mu \mathrm{m}$ can also be seen in the entire region, as marked in the inset of Fig. $2 \mathrm{f}$, and a number of irregular corrosion holes and micro-cracks can be observed, as shown in Ellipse D of Fig. 2g and Ellipse E of Fig. 2h.

The time evolution of pit propagation in the large pit case was further investigated by SEM of surfaces corroded under different immersion durations. Fig. 3 shows the typical pitting morphologies of as-machined and LSPed specimens after pitting corrosion in Therminol 72 solution at $250{ }^{\circ} \mathrm{C}$ for $200 \mathrm{~h}$. Figs. 3a-3d show the typical pitting morphology of the as-machined specimen at different magnifications. Figs. 3a and $3 \mathrm{~d}$ show a number of corrosion pits with diameters of about $30 \mu \mathrm{m}$ and certain depths at the top surface. These corrosion pits appear to be 
initiated within $72 \mathrm{~h}$ and increase in number as the corrosion time increases to $200 \mathrm{~h}$, as shown in Figs. $2 \mathrm{a}$ and $3 \mathrm{a}$. Fig. $2 \mathrm{~b}$ reveals that a number of small corrosion pits form massive smaller pits, and the diameters of these corrosion pits are about several micrometers. Some large corrosion pits further combine into larger pits, as shown in Fig. 3c, and corrosion holes with diameters of less than $3 \mu \mathrm{m}$ can be found at the top surface, as shown in Fig. 3d. Figs. 3c and 3d show that small corrosion holes may be found at the bottom of the large corrosion pit. Hence, the corrosion hole is the important corrosion method in this case.

Figs. $3 \mathrm{e}-3 \mathrm{~h}$ reveal the typical pitting morphologies of LSPed specimens with one coverage layer and an $8 \mathrm{~J}$ pulse energy at four magnification levels. The morphologies observed in these specimens are obviously different from those of the as-machined specimen in the same corrosion environment. Uniform and small corrosion pits can be easily found, and each corrosion pit grows independently without interactions with other pits, as shown in Fig. 3e. Some degree of corrosion spalling may be noted at the top surface of the LSPed specimens (as indicated in Ellipse E in Fig. 3f), and only a few corrosion holes can be observed (Fig. 3g). Typical corrosion pits after massive LSP treatment can be seen from Fig. 3h; these corrosion pits have an average diameter of 5-12 $\mu \mathrm{m}$.

The energy spectra of the as-machined and LSPed specimens after immersion in Therminol 72 solution at $250{ }^{\circ} \mathrm{C}$ for $200 \mathrm{~h}$ are shown in Figs. $4 \mathrm{a}$ and $4 \mathrm{~b}$. Fig. 4 shows that the $\mathrm{O}$ element contents of the as-machined and LSPed specimens are basically identical, thereby indicating that massive LSP treatment cannot prevent the oxidation reaction of AISI 4145 steel specimens at elevated temperature during pitting corrosion in Therminol 72 solution. However, considering the pitting morphologies and energy spectra obtained, massive LSP treatment appears to inhibit the 
extensive spalling of corrosion products and improve the pitting corrosion resistance of AISI 4145 steel in Therminol 72 solution. The Si element observed in both cases is attributed to residues of the abrasive paper used to prepare the working area of the specimens; such abrasion is difficult to eliminate even in an ultrasonic bath.

The corrosion reactions on the AISI 4145 steel surface in Therminol 72 solution at elevated temperature can be described as follows $[19,20]$ :

$$
\begin{aligned}
& 2 \mathrm{Fe}+3 \mathrm{Cl}_{2} \rightarrow 2 \mathrm{FeCl}_{3} \\
& 2 \mathrm{FeCl}_{3}+3 \mathrm{KOH} \rightarrow \mathrm{Fe}(\mathrm{OH})_{3}+3 \mathrm{KCl} \\
& 2 \mathrm{Fe}(\mathrm{OH})_{3} \rightarrow 3 \mathrm{Fe}_{2} \mathrm{O}_{3}+3 \mathrm{H}_{2} \mathrm{O}
\end{aligned}
$$

These reactions reveal that the corrosion product $\left[\mathrm{Fe}_{2} \mathrm{O}_{3}\right]$ is formed.

\subsection{Electrochemical corrosion performance and pitting morphologies}

Fig. 5 shows the open circuit potentials of as-machined specimen and the LSPed specimens with various coverage layers as a function of time in $0.598 \mathrm{~mol} / \mathrm{L} \mathrm{NaCl}$ solution. Before the onset of the potential sweep, the evolution of the open circuit potential was recorded. As can be seen in Figs. 5a and 5b, the open circuit potential is stabilized after 200 seconds immersion for the as-machined specimen and the LSPed specimen with one coverage layer of $8 \mathrm{~J}$. For the as-machined specimen, it can be seen that the open circuit potential is about $-1.3 \mathrm{~V}_{\mathrm{SCE}}$. After massive LSP treatment with one coverage layer of $8 \mathrm{~J}$, the open circuit potential stabilizes around $-1.136 \mathrm{~V}_{\mathrm{SCE}}$. For the LSPed specimens with two and three layers, it is seen that the open circuit potential drops rapidly until a knee point is reached upon in the solution and then it becomes constant. When 4145 steel specimen are treated by massive LSP treatment with multiple coverage layers of $8 \mathrm{~J}$, their open circuit potential values reach a stable state, and their open circuit potential 
values stabilize around $-0.90 \mathrm{~V}_{\mathrm{SCE}}$ and $-0.949 \mathrm{~V}_{\mathrm{SCE}}$, respectively, as shown in Fig. $5 \mathrm{c}$ and $5 \mathrm{~d}$. After the open circuit potential stabilizes, potentiodynamic polarisation curves and Nyquist plots are measured.

Potentiodynamic polarisation curves of as-machined specimen and the LSPed specimens with various coverage layers in $0.598 \mathrm{~mol} / \mathrm{L} \mathrm{NaCl}$ solution at room temperature are shown in Fig. 6. The pitting resistance of LSPed specimens is similar to that of the as-machined specimen. As indicated in Fig. 6 and Table 2, the pitting potential of the as-machined specimen is $-0.45 \mathrm{~V}_{\mathrm{SCE}}$, whereas those of the LSPed specimens with 1,2 and 3 coverage layers are $-0.40 \mathrm{~V}_{\mathrm{SCE}},-0.38 \mathrm{~V}_{\mathrm{SCE}}$ and $-0.37 \mathrm{~V}_{\mathrm{SCE}}$, respectively. Compared with that of the as-machined specimen, the pitting potential of the LSPed specimen with one coverage layer increases from $-0.45 \mathrm{~V}_{\mathrm{SCE}}$ to $-0.40 \mathrm{~V}_{\mathrm{SCE}}$, indicating improvements in repassivation ability. The experimental data shows gradual increases in pitting potential from $-0.40 \mathrm{~V}_{\mathrm{SCE}}$ to $-0.37 \mathrm{~V}_{\mathrm{SCE}}$ as the number of coverage layer increases from 1 to 3 . The passive current densities of the LSPed specimens significantly decrease to 50.12 $\mu \mathrm{A} / \mathrm{cm}^{2}$ (with one coverage layer), $0.47 \mu \mathrm{A} / \mathrm{cm}^{2}$ (with two coverage layers) and $0.60 \mu \mathrm{A} / \mathrm{cm}^{2}$ (with three coverage layers) compared with the $177.83 \mu \mathrm{A} / \mathrm{cm}^{2}$ value obtained from the as-machined specimen. The corresponding values of corrosion potential, corrosion current density, passive potential range, and passive potential can be seen in Table 2.

Fig. 6 suggests that the coverage layer of massive LSP treatment plays a significant role in the electrochemical corrosion resistance of AISI 4145 steel. As the number of coverage layer increases, the free corrosion potential of AISI 4145 steel moves toward the positive direction as the corrosion current density decreases. The passivation current density is an important parameter to consider during pitting corrosion resistance evaluation. Lower passivation current densities 
result in better pitting corrosion resistance [9]. Compared with the passivation current density of the as-machined specimen, those of the LSPed specimens decrease but tend to stabilise when the number of coverage layers exceeds two. Passivation occurs because of the formation of AISI 4145 steel corrosion products in $0.598 \mathrm{~mol} / \mathrm{L} \mathrm{NaCl}$ solution. The above research is consistent with the previous publication $[13,9]$.

The electrochemical reactions of AISI 4145 steel in $0.598 \mathrm{~mol} / \mathrm{L} \mathrm{NaCl}$ solution at room temperature are as follows $[21,22]$ :

$$
\begin{aligned}
& \mathrm{Fe} \rightarrow \mathrm{Fe}^{2+}+2 \mathrm{e}^{-} \text {(anodic reaction) } \\
& 2 \mathrm{H}_{2} \mathrm{O}+\mathrm{O}_{2}+4 \mathrm{e}^{-} \rightarrow 4 \mathrm{OH}^{-}(\text {cathodic reaction })
\end{aligned}
$$

Then, the $\mathrm{OH}^{-}$ions react with $\mathrm{Fe}^{2+}$ ions to form ferrous hydroxide [23]:

$$
\mathrm{Fe}^{2+}+2 \mathrm{OH}^{-} \rightarrow \mathrm{Fe}(\mathrm{OH})_{2}
$$

This is oxidised to ferric hydroxide $\mathrm{Fe}(\mathrm{OH})_{3}$, which is a simple form of rust, and the final product is the familiar reddish brown rust $\mathrm{Fe}_{2} \mathrm{O}_{3} \cdot \mathrm{H}_{2} \mathrm{O}$. this process can be written as the following reactions [24]:

$$
\begin{aligned}
& 4 \mathrm{Fe}(\mathrm{OH})_{2}+\mathrm{O}_{2}+2 \mathrm{H}_{2} \mathrm{O} \rightarrow 4 \mathrm{Fe}(\mathrm{OH})_{3} \\
& 2 \mathrm{Fe}(\mathrm{OH})_{3} \rightarrow 3 \mathrm{Fe}_{2} \mathrm{O}_{3}+3 \mathrm{H}_{2} \mathrm{O} \text { (corrosion products) }
\end{aligned}
$$

EIS tests were conducted at open circuit potential for 30 min with an $\mathrm{AC}$ amplitude of $10 \mathrm{mV}$ and sampling rate of 10 points per decade. Fig. 7 shows typical Nyquist plots of as-machined specimen and three kinds of LSPed specimens with $1 \mathrm{~cm}^{2}$ in $0.598 \mathrm{~mol} / \mathrm{L} \mathrm{NaCl}$ solution at room temperature for $30 \mathrm{~min}$ after the open circuit potential reaches a steady state. The radius of the capacitive impedance loop $R_{p}$ can be obtained from the EIS experiment. Fig. 7 also shows that the radius of the capacitive impedance loop for the as-machined specimen is lower than any of the 
radii obtained for the LSPed specimens. For the LSPed specimens, the radius of the capacitive impedance loop obtained with one coverage layer is obviously lower than that obtained with two coverage layers. Interestingly, however, the radius of the capacitive impedance loop remains stable as the number of coverage layer varies from two to three. The radius of the capacitive impedance loop $R_{p}$ is well known to be an important parameter used to evaluate the pitting corrosion resistance of metallic materials. The greater the radius of the capacitive impedance loop, the better the pitting corrosion resistance [4]. Compared with the radius of the as-machined specimen, the $R_{p}$ values of the LSPed specimens increase with increasing coverage layer. Hence, massive LSP treatment causes obvious increases in pitting potential and large decreases in passive current density. These outcomes indicate that massive LSP treatment clearly improves the pitting corrosion resistance of AISI 4145 steel and that this resistance gradually increases with increasing coverage layer.

Figs. $8 \mathrm{a}-8 \mathrm{c}$ show the typical pitting morphologies of the as-machined specimen in 0.598 $\mathrm{mol} / \mathrm{L} \mathrm{NaCl}$ solution after electrochemical testing. A number of non-uniform corrosion pits with diameters of about 20-35 $\mu \mathrm{m}$ may be clearly observed in the figures, and these corrosion pits exhibit a certain depth. Some micro-cracks can also be found at the top surface of the specimen. Figs. 9-11 show the typical pitting morphologies of LSPed specimens with different coverage layers in $0.598 \mathrm{~mol} / \mathrm{L} \mathrm{NaCl}$ solution after electrochemical testing. The average diameters of the corrosion pits are about 3,2.5 and $2 \mu \mathrm{m}$ when the number of coverage layers is 1,2 and 3 , respectively. In addition, the distribution of corrosion pits becomes more uniform as the coverage layer of massive LSP treatment increases. No micro-crack initiation may be observed on the LSPed specimen surfaces, as shown in Figs. 9-11. 
Fig. 12 shows the energy spectra of the four specimens obtained after electrochemical corrosion. Whilst $\mathrm{O}$ elements are clearly present in the four specimens, Fe element contents in the corroded surface of the as-machined specimen are lower than those in the corroded surfaces of the LSPed specimens. Thus, the iron oxides of the as-machined specimen surface are destroyed after electrochemical corrosion. Similar Fe contents are noted amongst LSPed specimens with two and three coverage layers.

In metallic materials, the relationship between pitting morphology and electrochemical property indicates that higher pitting potentials result in higher corrosion resistance and that lower passive current densities lead to better pitting corrosion resistance. The free-corrosion potentials of the LSPed specimens ( Figs. 9-11) are higher than that of the as-machined specimen (Fig. 8); however, the free-corrosion and passive current densities of the former Figs. 9-11) are lower than those of the latter (Fig. 8). Therefore, massive LSP treatment causes an obvious increase in pitting potential and a large decrease in passive current density. These outcomes indicate that massive LSP treatment improves the pitting corrosion resistance of AISI 4145 steel and that corrosion resistance increases with increasing coverage layer of massive LSP treatment.

\subsection{Influence mechanism of coverage layer during massive LSP treatment on corrosion resistance}

The corrosion behaviour of metallic materials strongly depends on the micro-structural characteristics and mechanical properties of their surface layer [25]. Sections 3.1 and 3.2 reveal that massive LSP treatment significantly improves the pitting corrosion resistance of AISI 4145 steel and effectively inhibits the formation of corrosion pits to improve the corrosion resistance of AISI 4145 steel in Therminol 72 solution at high temperature.

Fig. 13 shows the surface and in-depth residual stress distributions along the $\mathrm{X}$ direction of 
as-machined and LSPed specimens. As shown in Fig. 13a, the surface residual stress of the as-machined specimen, which exists in the zero-stress state, is approximately $-5 \mathrm{MPa}$. However, after massive LSP treatment, the average values of surface residual stress for of the three LSPed specimens are $-96,-347$ and $-418 \mathrm{MPa}$, respectively. The residual stress profiles of the three types of LSPed specimens in the depth direction are presented in Fig. 13b. The as-machined specimen is approximately in the zero-stress state; therefore, the effect of initial stress on shock waves may be ignored. After massive LSP treatment with one coverage layer and a pulse energy of $4 \mathrm{~J}$, the maximum of $-96 \mathrm{MPa}$ may be found at the top surface of the LSPed specimen. Moreover, the compressive residual stress decreases gradually with increasing distance to the top surface up to a depth of approximately $400 \mu \mathrm{m}$. After massive LSP treatment with one coverage layer and a pulse energy of $8 \mathrm{~J}$, a residual stress of $-347 \mathrm{MPa}$ may be observed at the top surface of the treated steel. A residual stress trend in the in-depth direction similar to that in the previous case is observed; however, the decrease in the compressive residual stress rate of the latter is obviously higher than that of the former. After successive massive LSP treatment with one coverage layer and a pulse energy of $8 \mathrm{~J}$, the maximum compressive residual stress in the treated sample remains unchanged compared with that in the specimen with one coverage layer and a pulse energy of $8 \mathrm{~J}$, but the decrease in the compressive residual stress rate with two coverage layers is obviously higher than that with one coverage layer. The first coverage layer with a pulse energy of $8 \mathrm{~J}$ generates a depth of about $500 \mu \mathrm{m}$ in compressive residual stress; the successive coverage layer with a pulse energy of $8 \mathrm{~J}$ increases this depth up to $550 \mu \mathrm{m}$, as shown in Fig. $13 \mathrm{~b}$. These results demonstrate that coverage layer and pulse energy during LSP treatment are important factors affecting the depth and maximum value of residual stress in treated samples. 
High temperature corrosion and electrochemical corrosion are processes that initially form oxide films and subsequently destroy these films. Oxide film formation consists of four stages, namely, (a) adsorption, (b) nucleation growth, (c) film growth and (d) rupture. Compared with the poor corrosion resistance of as-machined specimen, all of the LSPed specimens exhibit excellent resistance to pitting corrosion in both Therminol 72 solution at $250{ }^{\circ} \mathrm{C}$ and $0.598 \mathrm{~mol} / \mathrm{L} \mathrm{NaCl}$ solution at room temperature. Metallic components under an applied or tensile residual stress can deteriorate further by SCC in wet and humid environments containing chloride ions [26]. In our previous work, we found that the crack growth threshold increases and the crack growth rate decreases under compressive residual stress, consequently increasing the failure stress intensity factor during crack growth testing. However, surface failure often occurs because of tensile residual stress development on the outside surface of metallic material through rupture of passivation films at the crack tip. Cracks grow rapidly from the bare metal exposed until the crack tip can repassivate or grow slowly to failure.

Fig. 14 presents typical cross-sectional SEM morphologies in the near-surface layer of the as-machined and three types of LSPed specimens immersed in the professional etching reagent for $5 \mathrm{~s}$ at room temperature. Fig. 14a shows some linear pearlite or strip-like pearlite (i.e., the white area marked with yellow solid arrows) at the cross-section of the as-machined specimen; the pearlite content in this specimen is obviously less than that of ferrite (i.e., the grey area marked with yellow hidden arrows). Linear pearlite clearly increases after massive LSP treatment with one coverage layer and a pulse energy of $4 \mathrm{~J}$, and no difference in pearlite and ferrite contents is found at the cross-section, as shown in Fig. 14b. After massive LSP treatment with one coverage layer and a pulse energy of $8 \mathrm{~J}$, the pearlite content exceeds that of ferrite, and sheet-like pearlite with a 
large area may be found at the cross-section, as shown in Fig. 14c. After successive massive LSP treatment with one coverage layer and a pulse energy of $8 \mathrm{~J}$, strip-like pearlite with a large area is found at the majority of the cross-section, as shown in Fig. 14d. In fact, as the coverage layer increases, large blocky carbides develop at the ferrite grain boundaries. The cross-sections with different coverage layers and a pulse energy of $8 \mathrm{~J}$ consist of ferrite, pearlite and grain boundary carbides (Figs. 14c and 14d). In the previous work, it has been found that pearlite has atypical lamellar structure consisting of alternating layers of ferrite and cementite $\left(\mathrm{Fe}_{3} \mathrm{C}\right)$, and $\mathrm{Fe}_{3} \mathrm{C}$ can improve the mechanical properties [27], which may be helpful to improve the pit corrosion resistance. Based from the above experimental data, massive LSP treatment can break linear pearlite or strip-like pearlite into smaller pearlite. Furthermore, higher pulse energies and more coverage layers can increase the pearlite content and improve the uniform distribution of pearlite and large blocky carbides in the near-surface layer of AISI 4145 steel during massive LSP treatment.

Pitting corrosion is a form of extremely localised corrosion that leads to the creation of small holes on the top surface of metallic materials. Medium carbon steel, such as AISI 4145 steel, consists of ferrite and pearlite, and the corrosion resistance of steel depends on the diameter and weight ratio of these components. The effects of coverage layer during massive LSP treatment on pitting corrosion in the standard corrosive solution are schematically illustrated in Fig. 15. Whereas the as-machined specimen has poor pitting corrosion resistance in the standard corrosive solution containing chloride ions, all of the LSPed specimens exhibit good pitting corrosion resistance. This phenomenon can be explained in several aspects. Firstly, the surface residual stress is zero in the as-machined specimen, whilst those in the LSPed specimens with one and two 
coverage layers are -347 and $-418 \mathrm{MPa}$ with depths of 500 and $550 \mu \mathrm{m}$, respectively, as shown in Fig. 13. Secondly, pitting corrosion is well known to be strongly affected by the micro-structural characteristics of medium carbon steel [25]. The as-machined specimen consists of linear pearlite or strip-like pearlite and ferrite, and the pearlite content is obviously less than the ferrite content, as shown in Fig. 14a. By comparison, besides pearlite and ferrite, some carbide can be found at the ferrite grain boundaries of the cross-sections of LSPed specimens, as shown in Figs. 14c and 14d. Massive LSP treatment also breaks linear pearlite or strip-like pearlite into smaller particle, thereby indicating massive LSP treatment refines coarse grains in the surface layer of as-machined specimens.

High-level compressive residual stress and grain refinement are beneficial in retarding SCC initiation in the standard corrosive solution containing chloride ions [12,13]. Thus, after the electrochemical test, non-uniform corrosion pits measuring about 20-35 $\mu \mathrm{m}$ and a certain depth (as shown in Fig. 15a) are obviously seen at the top surface of the as-machined specimen; by contrast, uniform corrosion pits of approximately 2.5 and $\sim 2 \mu \mathrm{m}$ (as shown in Figs. 15b and 15c) were noted at the top surfaces of the LSPed specimens with one and two coverage layers, respectively. Hence, compared with the as-machined specimen, the LSPed specimens exhibit good pitting corrosion resistance in Therminol 72 solution at $250{ }^{\circ} \mathrm{C}$ and $0.598 \mathrm{~mol} / \mathrm{L} \mathrm{NaCl}$ solution at room temperature. Moreover, the pitting corrosion resistance of LSPed specimens consistently increases with increasing coverage layer. The combination of residual stress and microstructural distribution caused by massive LSP treatment leads to increased resistance toward pitting corrosion.

\section{Conclusions}


(1) Massive LSP treatment can effectively inhibit the massive spalling of corrosion product which may be significantly improve the corrosion resistance of AISI 4145 steel in Therminol 72 solution at an elevated temperature of $250{ }^{\circ} \mathrm{C}$.

(2) In $0.598 \mathrm{~mol} / \mathrm{L} \mathrm{NaCl}$ solution at room temperature, the LSPed specimens exhibit an obvious increase in pitting potential and a significant decrease in passive current density compared with as-machined specimens. Furthermore, the electrochemical corrosion resistance increases with increasing coverage layer of massive LSP treatment.

(3) Massive LSP treatment breaks linear pearlite or strip-like pearlite into smaller pearlite. Higher pulse energies and more coverage layers increase pearlite contents and cause uniform pearlite distributions. Meanwhile, the presence of large blocky carbides in the near-surface layer of AISI 4145 steel is also observed.

(4) The influence process of massive LSP treatment with multiple layers on the pitting corrosion behaviour of AISI 4145 steel in a standard corrosive solution is clearly presented, and this phenomenon may be attributed to the existence of high-level compressive residual stresses in the surface layer of the steel as well as uniform microstructural distribution induced by massive LSP treatment.

\section{Acknowledgements}

The authors are grateful for the support provided by National Natural Science Foundation of China (No. 51575242), Natural Science Foundation of Jiangsu Province in China (Nos. BK20140012, BE2016148, BK20151341, and 1501140B), China Postdoctoral Science Special Foundation (No. 2015T80504), and Six Major Talent Peak of Jiangsu Province 
(2014-ZBZZ-015).

\section{References:}

[1] C. Ye, S. Suslov, X.L. Fei, G.J. Cheng, Bimodal nanocrystallization of NiTi shape memory alloy by laser shock peening and post-deformation annealing, Acta Mater. 59 (2011) 7219-7227. [2] C.S. Montross, T. Wei, L. Ye, G. Clark, Y.W. Mai, Laser shock processing and its effects on microstructure and properties of metal alloys: a review, Int. J. Fatigue 24 (2002) 1021-1036.

[3] U. Trdan, J. Grum, SEM/EDS characterization of laser shock peening effect on localized corrosion of Al alloy in a near natural chloride environment, Corros. Sci. 82 (2014) 328-338.

[4] U. Trdan, J. Grum, Evaluation of corrosion resistance of AA6082-T651 aluminium alloy after laser shock peening by means of cyclic polarisation and ElS methods, Corros. Sci. 59 (2012) $324-333$.

[5] S. Kalainathan, S. Sathyajith, S. Swaroop, Effect of laser shot peening without coating on the surface properties and corrosion behavior of 316L steel, Opt. Lasers Eng. 50 (2012) 1740-1745.

[6] A. Telang, A.S. Gill, S. Teysseyre, S.R. Mannava, D. Qian, V.K. Vasudevan, Effects of laser shock peening on SCC behavior of Alloy 600 in tetrathionate solution, Corros. Sci. 90 (2015) $434-444$.

[7] H. Amar, V. Vignal, H. Krawiec, C. Josse, P. Peyre, S.N. Silva, L.F. Dick, Influence of the microstructure and laser shock processing (LSP) on the corrosion behaviour of the AA2050-T8 aluminium alloy. Corros. Sci. 53(2011) 3215-3221.

[8] H. Lim, P. Kim, H. Jeong, S. Jeong, Enhancement of abrasion and corrosion resistance of duplex stainless steel by laser shock peening, J. Mater. Process. Technol. 212 (2012) 1347-1354. [9] P. Peyre, X. Scherpereel, L. Berthe, C. Carboni, R. Fabbro, G. Béranger, C. Lemaitre, Surface modifications induced in 316L steel by laser peening and shot-peening. Influence on pitting corrosion resistance, Mater. Sci. Eng. A 280 (2000) 294-302.

[10] P. Peyre, C. Braham, J. Ledion, L Berthe, R. Fabbro, Corrosion reactivity of laser-peened 
steel surface, J. Mater. Eng. Perform. 9 (2000) 656-662.

[11] S. Kalainathan, S. Sathyajith, S. Swaroop, Effect of laser shot peening without coating on the surface properties and corrosion behavior of 316L steel, Opt. Lasers Eng. 50 (2012) 1740-1745.

[12] J.Z. Lu, K.Y. Luo, D.K. Yang, X.N. Cheng, J.L. Hu, F.Z. Dai, H. Qi, L. Zhang, J.S. Zhong, Q.W. Wang, Y.K. Zhang, Effects of laser peening on stress corrosion cracking (SCC) of ANSI 304 austenitic stainless steel, Corros. Sci. 60 (2012) 145-152.

[13] J.Z. Lu, H. Qi, K.Y. Luo, M. Luo, X.N. Chen, Corrosion behaviour of AISI 304 stainless steel subjected to massive laser shock peening impacts with different pulse energies, Corros. Sci. 80 (2014) 53-59.

[14] H.S. Lee, D.S. Kim, J.S. Jung, Y.S. Pyoun, K. Shin, Influence of peening on the corrosion properties of AISI 304 stainless steel. Corros. Sci. 51 (2009) 2826-2830.

[15] J.Z. Lu, K.Y. Luo, Y.K. Zhang, C.Y. Cui, G.F. Sun, J.Z. Zhou, L. Zhang, J. You, K.M. Chen, J.W. Zhong, Grain refinement of LY2 aluminum alloy induced by ultra-high plastic strain during multiple laser shock processing impacts, Acta Mater. 58 (2010) 3984-3994.

[16] K.Y. Luo, C.Y. Wang, Y.M. Li, M. Luo, S. Huang, X.J. Hua, J.Z. Lu, Effects of laser shock peening and groove spacing on the wear behavior of non-smooth surface fabricated by laser surface texturing, Appl. Surf. Sci. 313 (2014) 600-606.

[17] L. Zhang, Y.K. Zhang, J.Z. Lu, F.Z. Dai, A.X. Feng, K.Y. Luo, J.S. Zhong, Q.W. Wang, M. Luo, H. Qi, Effects of laser shock processing on electrochemical corrosion resistance of ANSI 304 stainless steel weldments after cavitation erosion. Corros. Sci. 66 (2013) 5-13.

[18] A.P. Jivkov, Evolution of fatigue crack corrosion from surface irregularities, Theor. Appl. Fract. Mech. 40 (2003) 45-54.

[19] J. Metsäjoki, E. Huttunen-Saarivirta, T. Lepistö. Elevated-temperature corrosion of uncoated and aluminized 9-12\% Cr boiler steels beneath KCl deposit, Fuel 133 (2014) 173-181.

[20] S.N. Liu, Z.D. Liu, Y.T. Wang, J. Tang. A comparative study on the high temperature 
corrosion of TP347H stainless steel, C22 alloy and laser-cladding C22 coating in molten chloride salts, Corros. Sci. 83 (2014) 396-408.

[21] Y. Li, Y.F. Cheng, Effect of surface finishing on early-stage corrosion of a carbon steel studied by electrochemical and atomic force microscope characterizations, Appl. Surf. Sci. 366 (2016) 95-103.

[22] L.Y. Xu, Y.F. Cheng, Experimental and numerical studies of effectiveness of cathodic protection at corrosion defects on pipelines, Corros. Sci. 78 (2014) 162-171.

[23] L. Niu, Y.F. Cheng, Corrosion behavior of X-70 pipe steel in near-neutral pH solution, Appl. Surf. Sci. 253 (2007) 8626-8631.

[24] L.L. Shreir, R.A. Jarman, G.T. Burstein, Corrosion Volume I: Metal/ Environment Reactions, Third Ed., Butterworth-Heinemann, Oxford, 1994.

[25] S.R. Kumar, K. Gudimetla, P. Venkatachalam, B. Ravisankar, Stress corrosion cracking of Al7075 alloy processed by equal channel angular pressing, Int. J. Eng. Sci. Technol. 2 (2010) $53-61$.

[26] D.T. Spencer, M.R. Edwards, M.R. Wenman, C. Tsitsios, G.G. Scatigno, P.R. Chard-Tuckey, The initiation and propagation of chloride-induced transgranular stress-corrosion cracking (TGSCC) of 304L austenitic stainless steel under atmospheric conditions, Corros. Sci. 88, (2014) 76-88.

[27] X.H. Hao, J.H. Dong, I.N. Etim, J. Wei, W. Ke. Sustained effect of remaining cementite on the corrosion behavior of ferrite-pearlite steel under the simulated bottom plate environment of cargo oil tank, Corros. Sci. 110, (2016) 296-304. 


\section{List of Figure Captions}

Fig. 1 Dimensions and images of (a) pitting corrosion specimen in Therminol 72 solution and (b) electrochemical corrosion specimen in $0.598 \mathrm{~mol} / \mathrm{L} \mathrm{NaCl}$ solution at room temperature (Unit: $\mathrm{mm}$ ).

Fig. 2 Typical pitting morphologies of (a)-(d) as-machined specimen and (e)-(h) LSPed specimen with one coverage layer and a pulse energy of $8 \mathrm{~J}$ after hightemperature corrosion experiment in Therminol 72 high-temperature oil at $250{ }^{\circ} \mathrm{C}$ for 200 hours.

Fig. 3 Typical pitting morphologies of (a)-(d) as-machined specimen and (e)-(h) LSPed specimen with one coverage layer and a pulse energy of $8 \mathrm{~J}$ after hightemperature corrosion experiment in high-temperature oil at $250{ }^{\circ} \mathrm{C}$ for 72 hours.

Fig. 4 Energy spectrum of (a) as-machined specimen and (b) LSPed specimen after high-temperature corrosion experiment in Therminol 72 solution at a temperature of $250{ }^{\circ} \mathrm{C}$ for 200 hours.

Fig. 5 Time dependence of open circuit potential for 4145 steel specimens in 0.598 $\mathrm{mol} / \mathrm{L} \mathrm{NaCl}$ solution. (a) as-machined specimen, (b) with one coverage layer of $8 \mathrm{~J}$, (c) with two coverage layers of $8 \mathrm{~J}$, and (d) with three coverage layers of $8 \mathrm{~J}$.

Fig. 6 Potentiodynamic polarisation curves of AISI 4145 steel after immersed in 0.598 $\mathrm{mol} / \mathrm{L} \mathrm{NaCl}$ solution at different treatment parameters: (a) as-machined specimen, (b) with one coverage layer of $8 \mathrm{~J}$, (c) with two coverage layers of $8 \mathrm{~J}$, and (d) with three coverage layers of $8 \mathrm{~J}$.

Fig. 7 Typical Nyquist plots of as-machined specimen and three kinds of LSPed specimens with $1 \mathrm{~cm}^{2}$ in $0.598 \mathrm{~mol} / \mathrm{L} \mathrm{NaCl}$ solution at room temperature for $30 \mathrm{~min}$ after the open circuit potential reaches a steady state.

Fig. 8 Typical pitting morphologies of as-machined specimen after electrochemical 
corrosion experiment. (a) non-uniform corrosion pits, (b) typical corrosion pit with a size of $\sim 35 \mu \mathrm{m}$, and (c) typical micro-crack morphology.

Fig. 9 Typical pitting morphologies of LSPed specimen with one coverage layer and a pulse of $8 \mathrm{~J}$ after electrochemical corrosion experiment. (a) uniform and non-uniform corrosion pits, (b) magnified pitting morphologies of uniform corrosion pits, and (c) typical magnified corrosion pit with a size of $3 \mu \mathrm{m}$.

Fig. 10 Typical pitting morphologies of LSPed specimen with two coverage layers and a pulse of $8 \mathrm{~J}$ after electrochemical corrosion experiment. (a) uniform and small corrosion pits, (b) magnified pitting morphologies of uniform corrosion pits, and (c) typical corrosion pit with a size of $2.5 \mu \mathrm{m}$.

Fig. 11 Typical pitting morphologies of LSPed specimen with three coverage layers and a pulse of $8 \mathrm{~J}$ after electrochemical corrosion experiment. (a) whole pitting corrosion surface, (b) magnified uniform and small corrosion pits, and (c) typical corrosion pit with a size of $2 \mu \mathrm{m}$.

Fig. 12 Energy spectrums of four types of specimens after electrochemical corrosion testing. (a) as-machined specimen, (b) with one coverage layer and a pulse of $8 \mathrm{~J}$, (c) with two coverage layers and a pulse of $8 \mathrm{~J}$, and (d) with three coverage layers and a pulse of $8 \mathrm{~J}$.

Fig. 13 (a) Surface and (b) in-depth residual stress distributions of as-machined specimen and three types of LSPed specimens.

Fig. 14 Typical cross-sectional morphologies in the near surface layer of asmachined and three types of LSPed specimens immersed in the professional etching reagent for $5 \mathrm{~s}$ at room temperature. (a) as-machined specimen, (b) with one coverage layer and a pulse energy of $4 \mathrm{~J}$, (c) with one coverage layer and a pulse energy of $8 \mathrm{~J}$, and (d) with two coverage layers and a pulse energy of $8 \mathrm{~J}$. 
Fig. 15 Schematic diagram of coverage layer during massive LSP treatment on pitting corrosion resistance of AISI 4145 steel. (a) as-machined specimen, (b) LSPed specimen with one coverage layer, and (c) LSPed specimen with multiple coverage layers. 

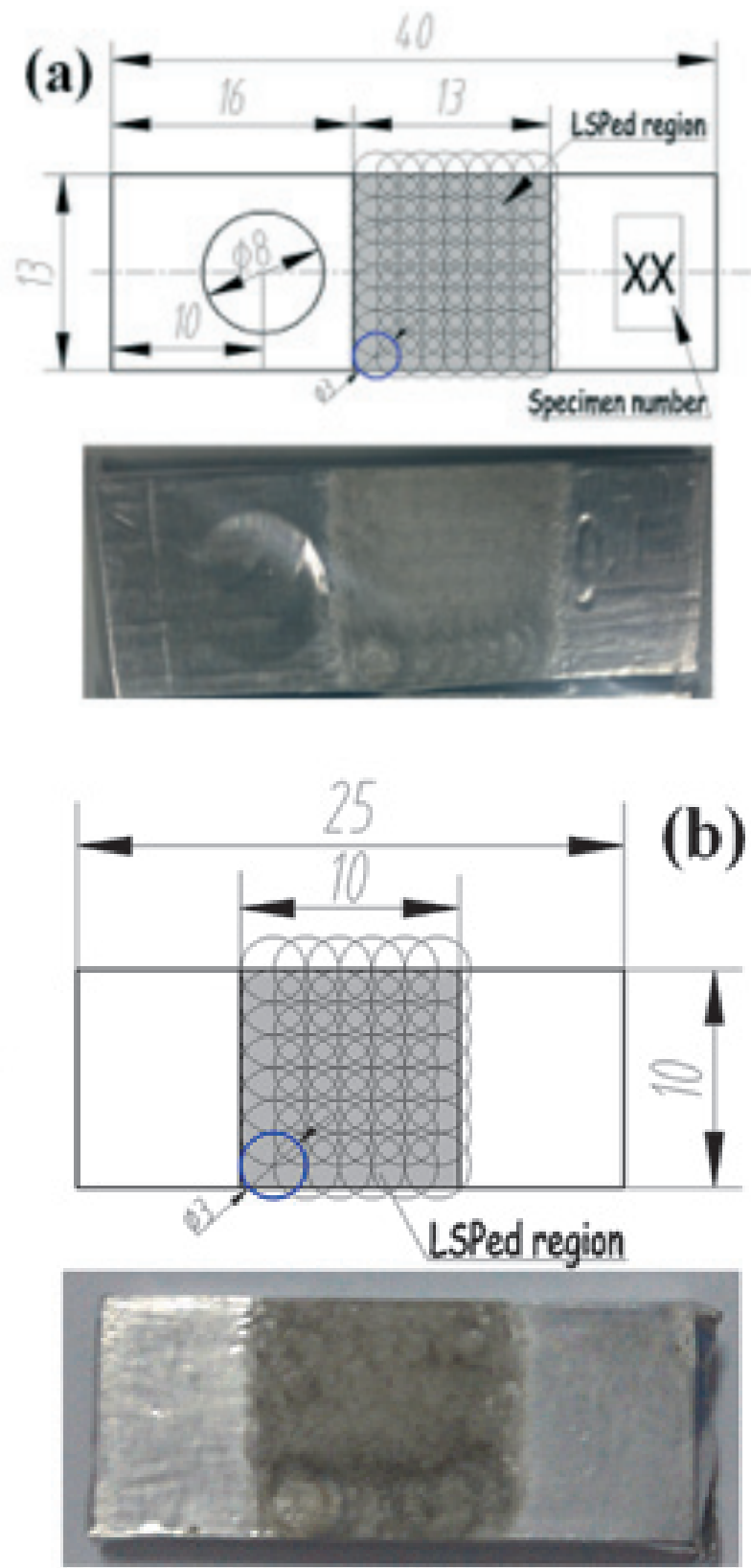

Fig. 1 Dimensions and images of (a) pitting corrosion specimen in Therminol 72 solution and (b) electrochemical corrosion specimen in $0.598 \mathrm{~mol} / \mathrm{L} \mathrm{NaCl}$ solution at room temperature (Unit: $\mathrm{mm}$ ). 

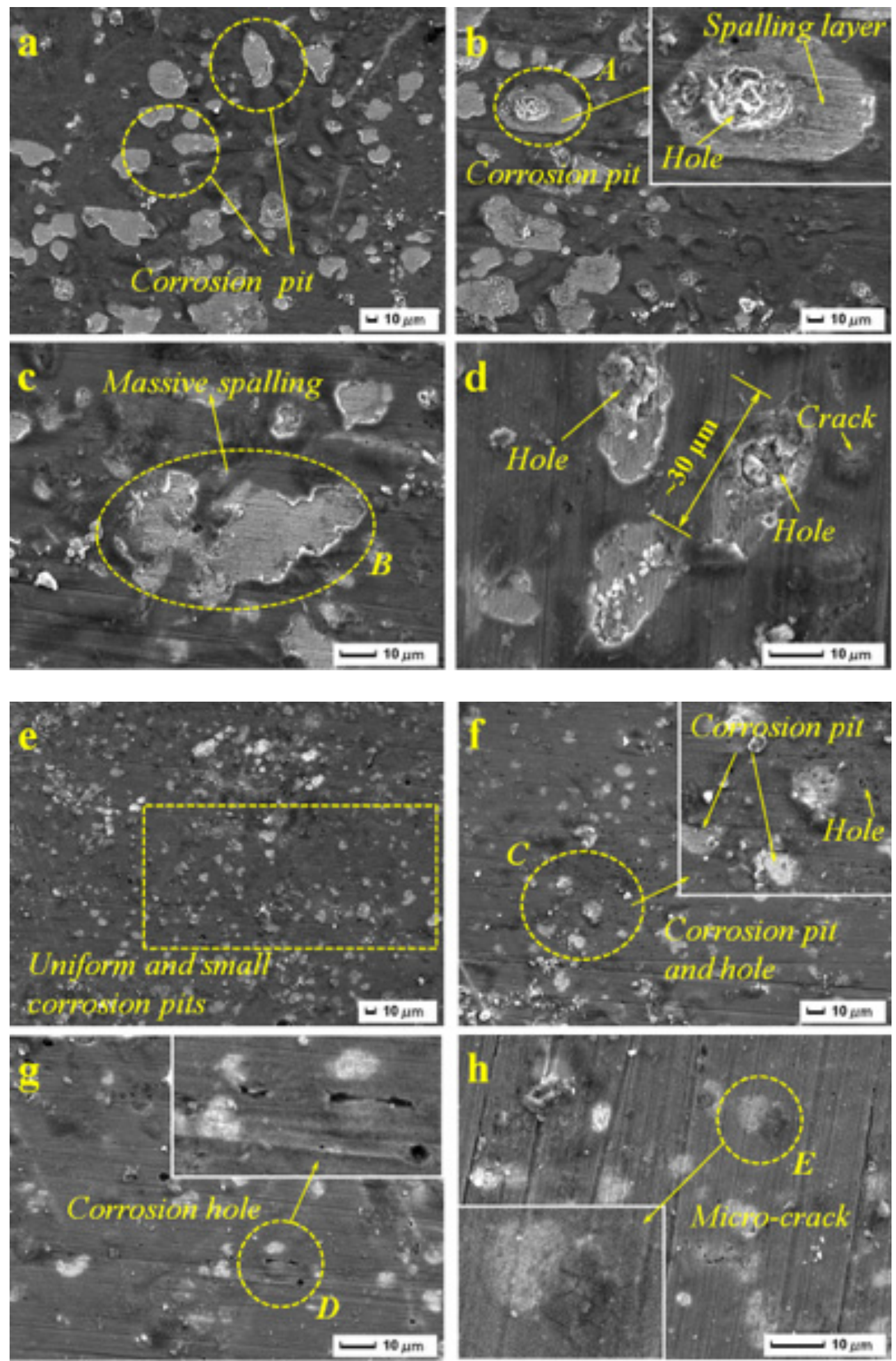

Fig. 2 Typical pitting morphologies of (a)-(d) as-machined specimen and (e)-(h)

LSPed specimen with one coverage layer and a pulse energy of $8 \mathrm{~J}$ after hightemperature corrosion experiment in Therminol 72 high-temperature oil at $250{ }^{\circ} \mathrm{C}$ for 200 hours. 

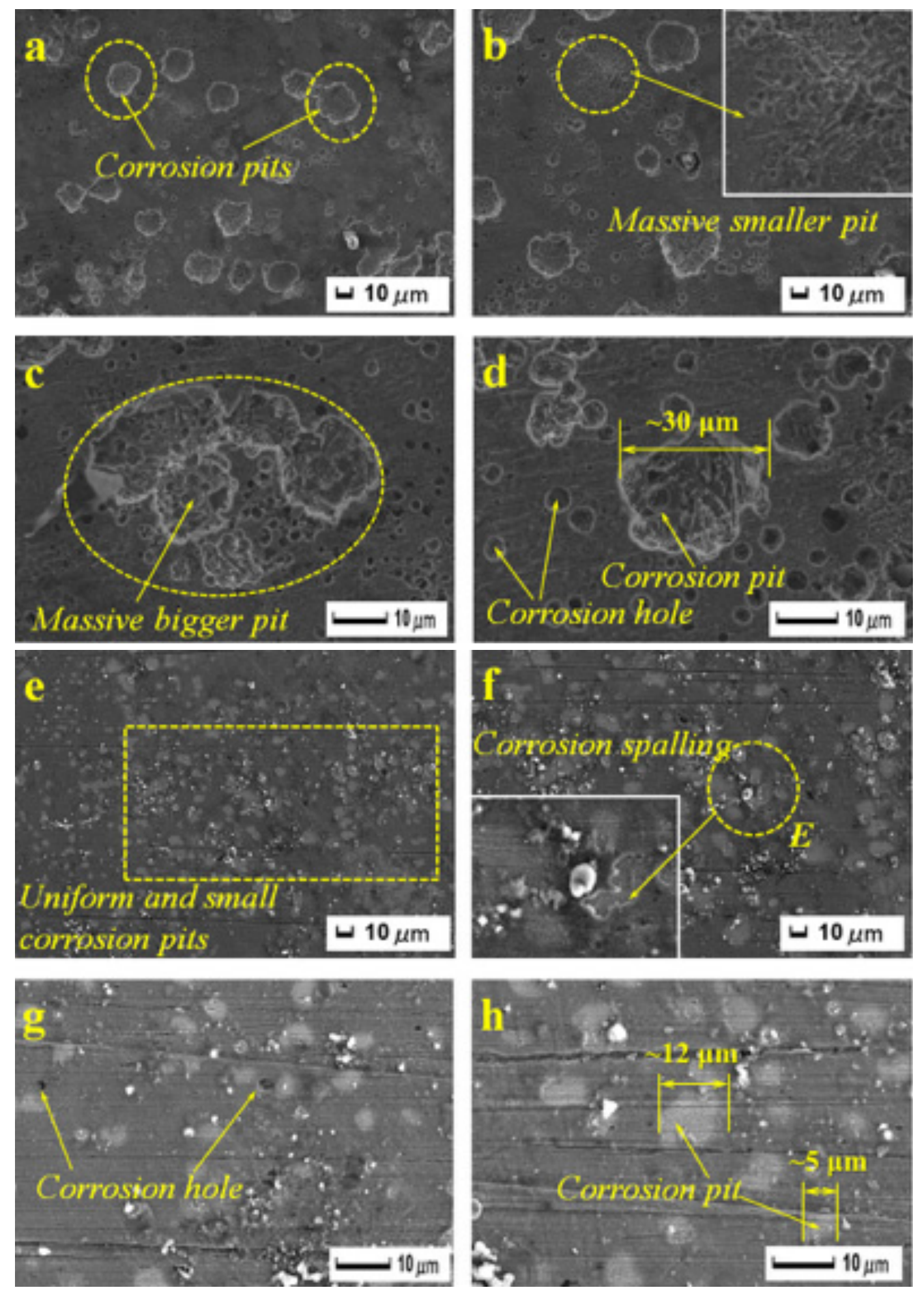

Fig. 3 Typical pitting morphologies of (a)-(d) as-machined specimen and (e)-(h)

LSPed specimen with one coverage layer and a pulse energy of $8 \mathrm{~J}$ after hightemperature corrosion experiment in high-temperature oil at $250{ }^{\circ} \mathrm{C}$ for 72 hours. 


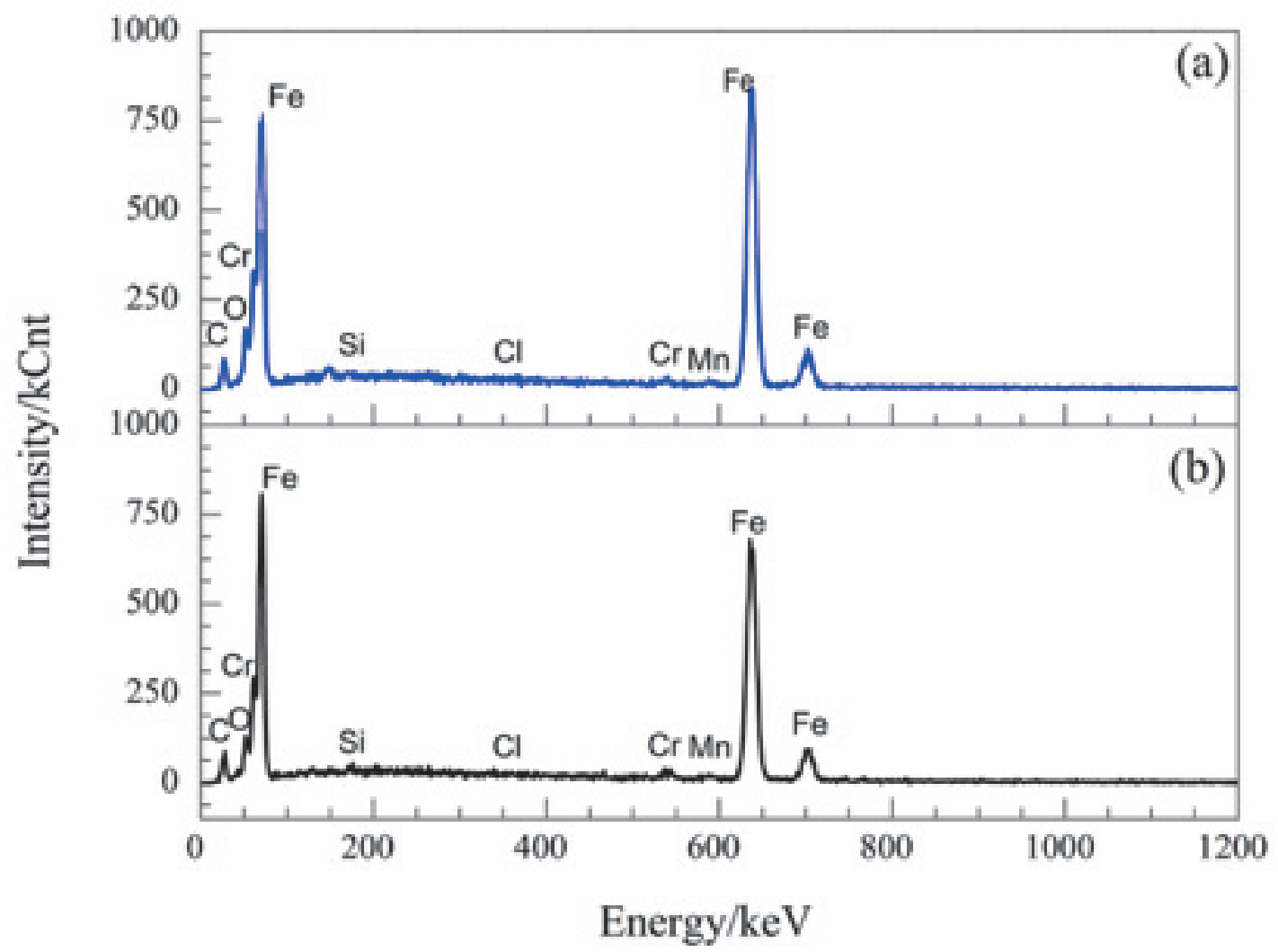

Fig. 4 Energy spectrum of (a) as-machined specimen and (b) LSPed specimen after high-temperature corrosion experiment in Therminol 72 solution at a temperature of $250{ }^{\circ} \mathrm{C}$ for 200 hours. 

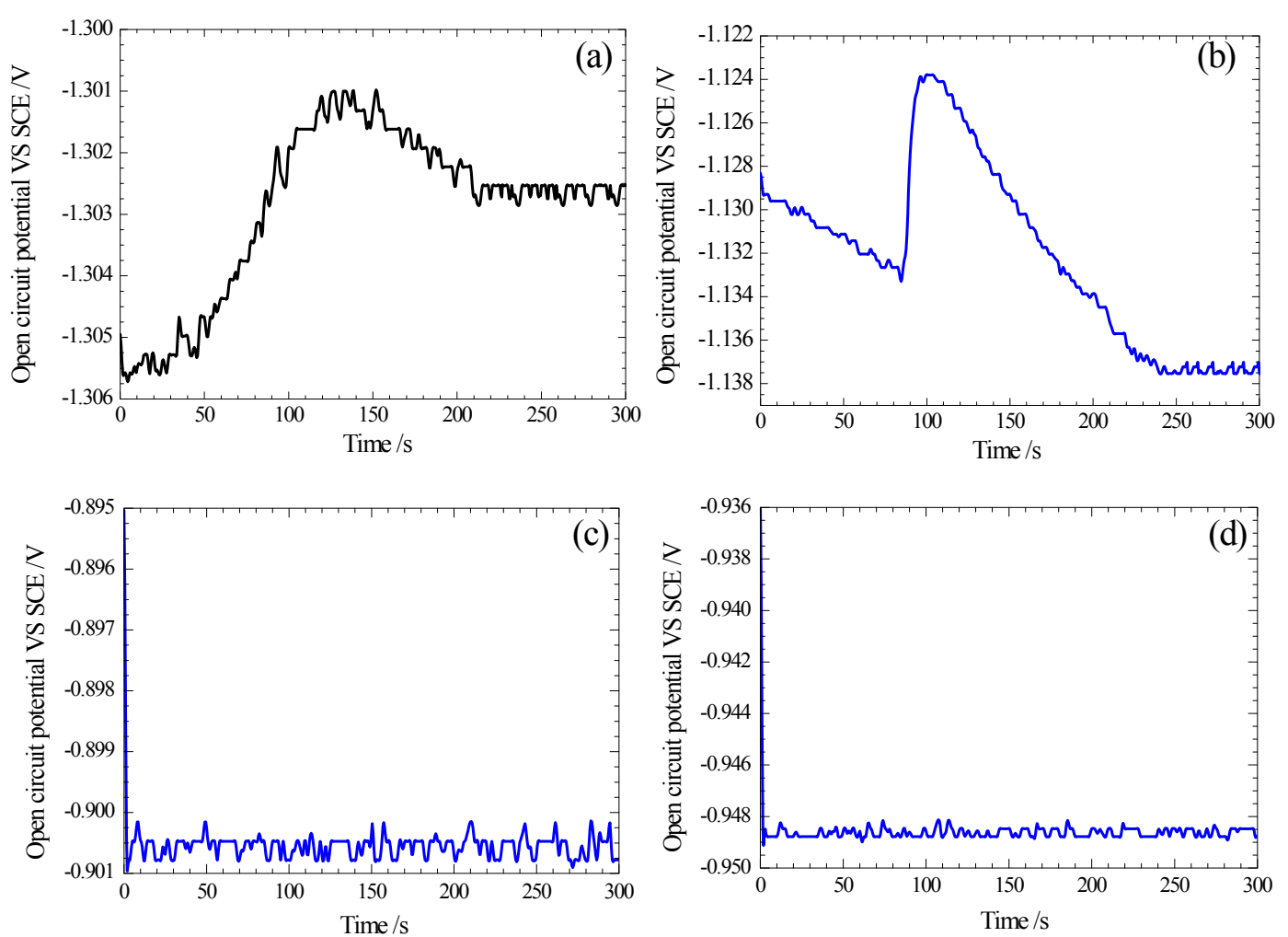

Fig. 5 Time dependence of open circuit potential for 4145 steel specimens in 0.598 $\mathrm{mol} / \mathrm{L} \mathrm{NaCl}$ solution. (a) as-machined specimen, (b) with one coverage layer of $8 \mathrm{~J}$, (c) with two coverage layers of $8 \mathrm{~J}$, and (d) with three coverage layers of $8 \mathrm{~J}$. 


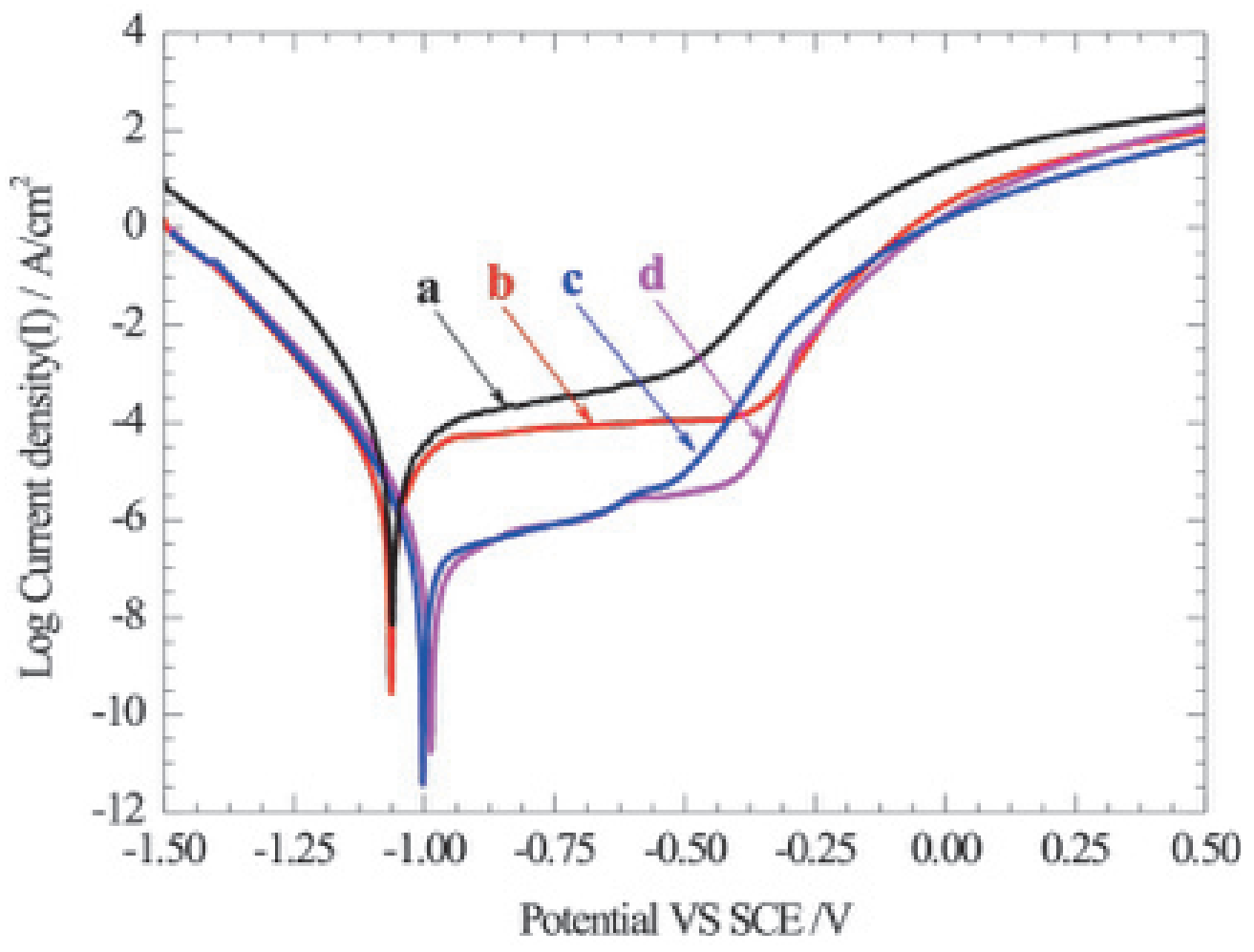

Fig. 6 Potentiodynamic polarisation curves of AISI 4145 steel after immersed in 0.598 $\mathrm{mol} / \mathrm{L} \mathrm{NaCl}$ solution at different treatment parameters: (a) as-machined specimen, (b) with one coverage layer of $8 \mathrm{~J}$, (c) with two coverage layers of $8 \mathrm{~J}$, and (d) with three coverage layers of $8 \mathrm{~J}$. 


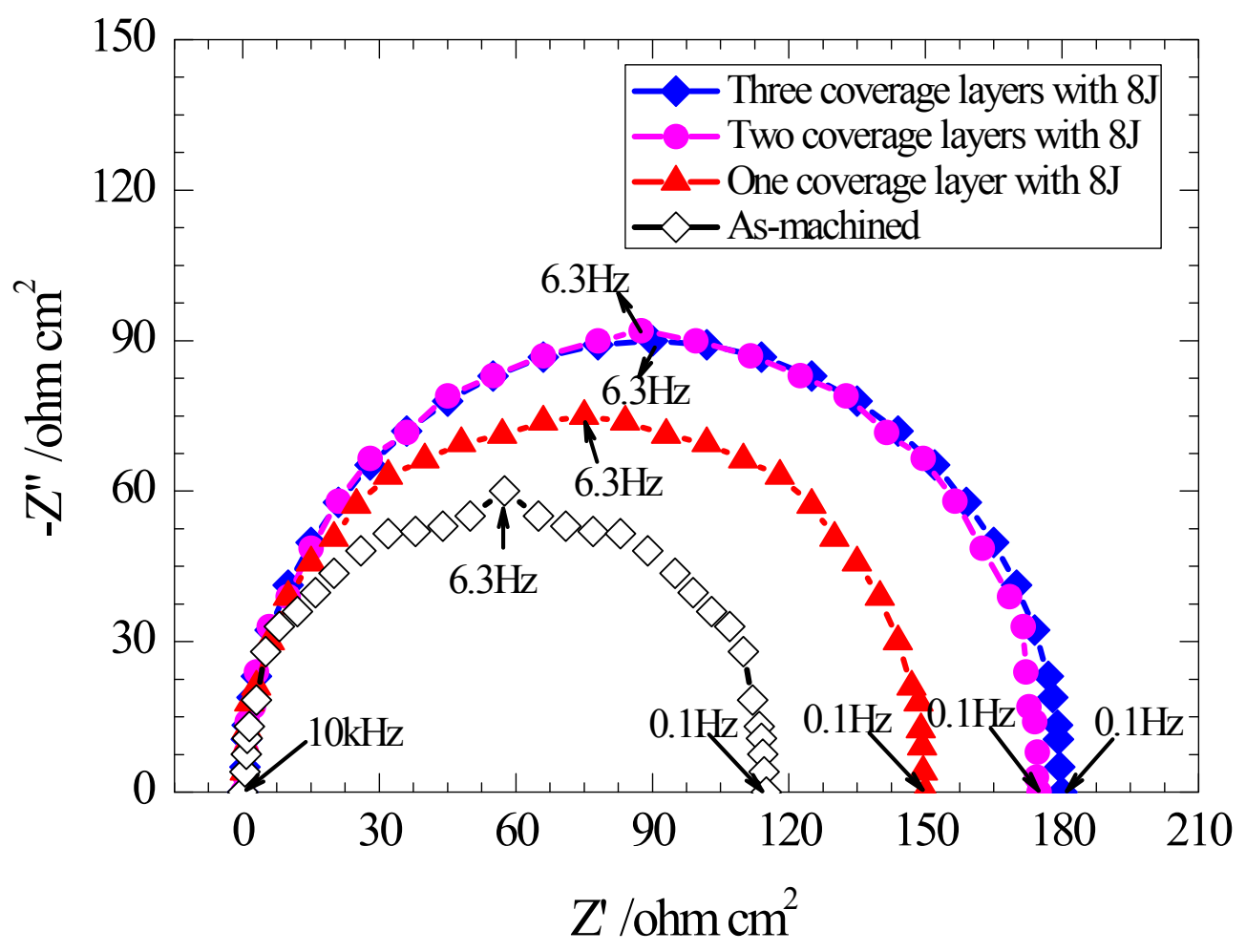

Fig. 7 Typical Nyquist plots of as-machined specimen and three kinds of LSPed specimens with $1 \mathrm{~cm}^{2}$ in $0.598 \mathrm{~mol} / \mathrm{L} \mathrm{NaCl}$ solution at room temperature for $30 \mathrm{~min}$ after the open circuit potential reaches a steady state. 

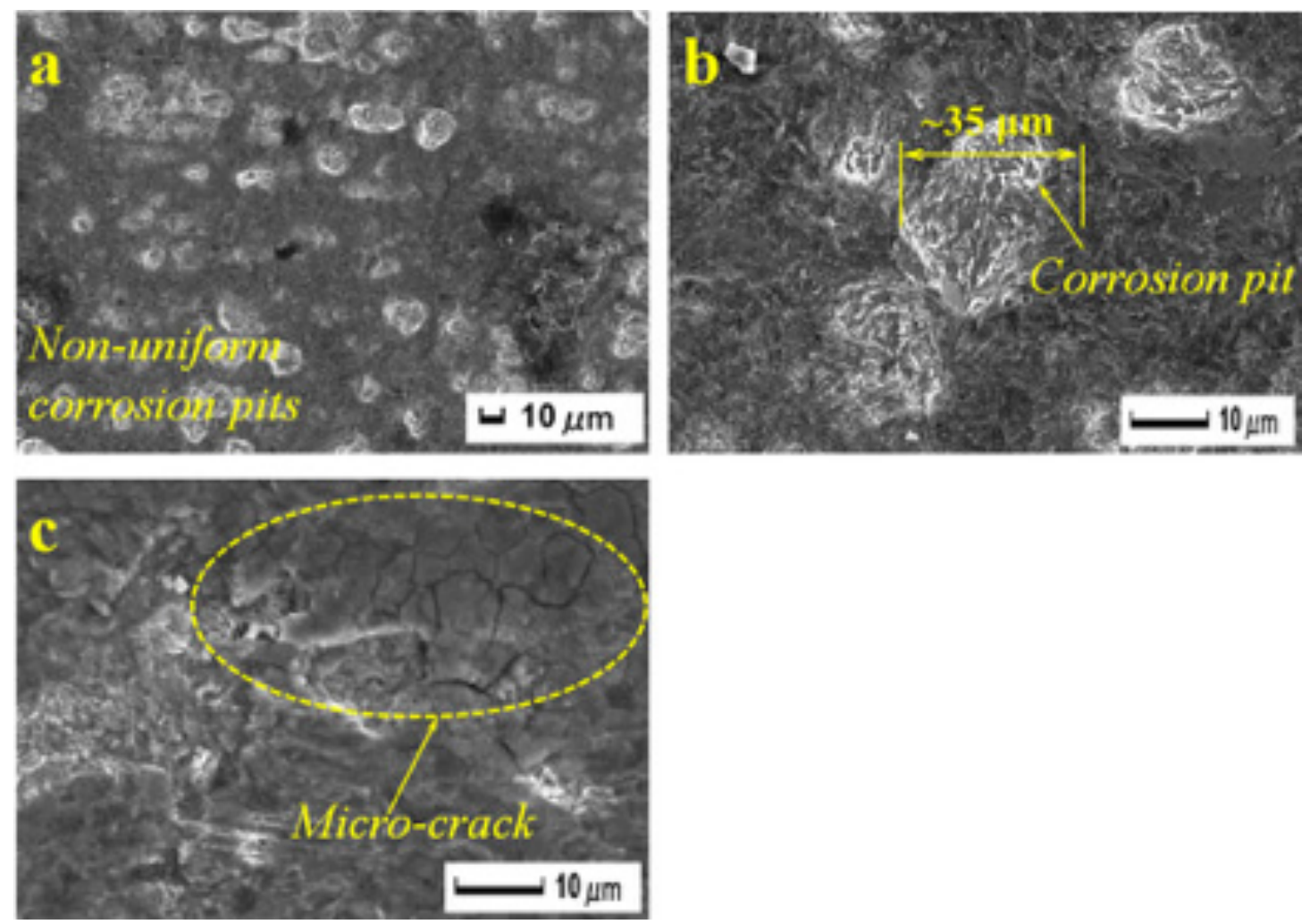

Fig. 8 Typical pitting morphologies of as-machined specimen after electrochemical corrosion experiment. (a) non-uniform corrosion pits, (b) typical corrosion pit with a size of $\sim 35 \mu \mathrm{m}$, and (c) typical micro-crack morphology. 

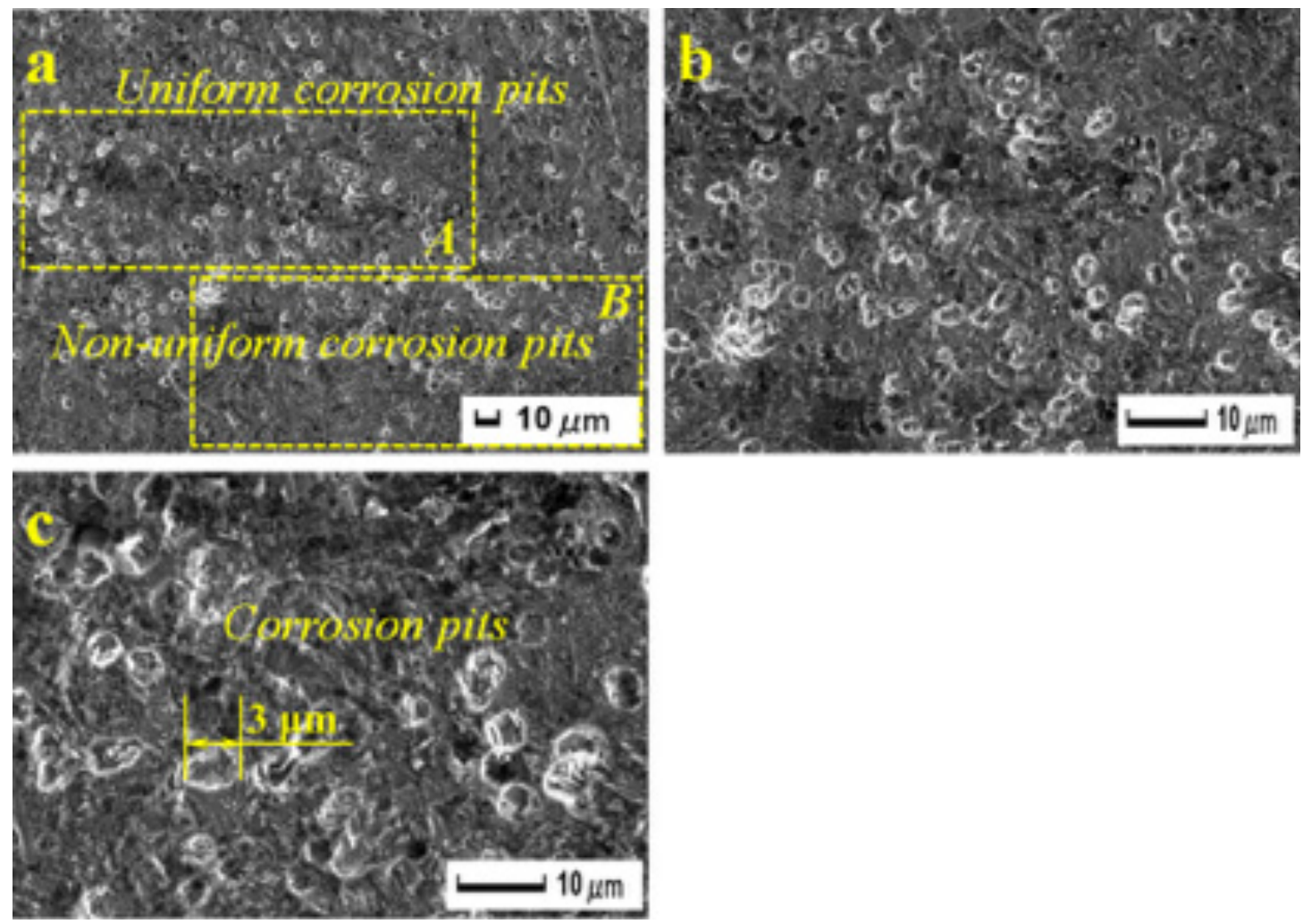

Fig. 9 Typical pitting morphologies of LSPed specimen with one coverage layer and a pulse of $8 \mathrm{~J}$ after electrochemical corrosion experiment. (a) uniform and non-uniform corrosion pits, (b) magnified pitting morphologies of uniform corrosion pits, and (c) typical magnified corrosion pit with a size of $3 \mu \mathrm{m}$. 

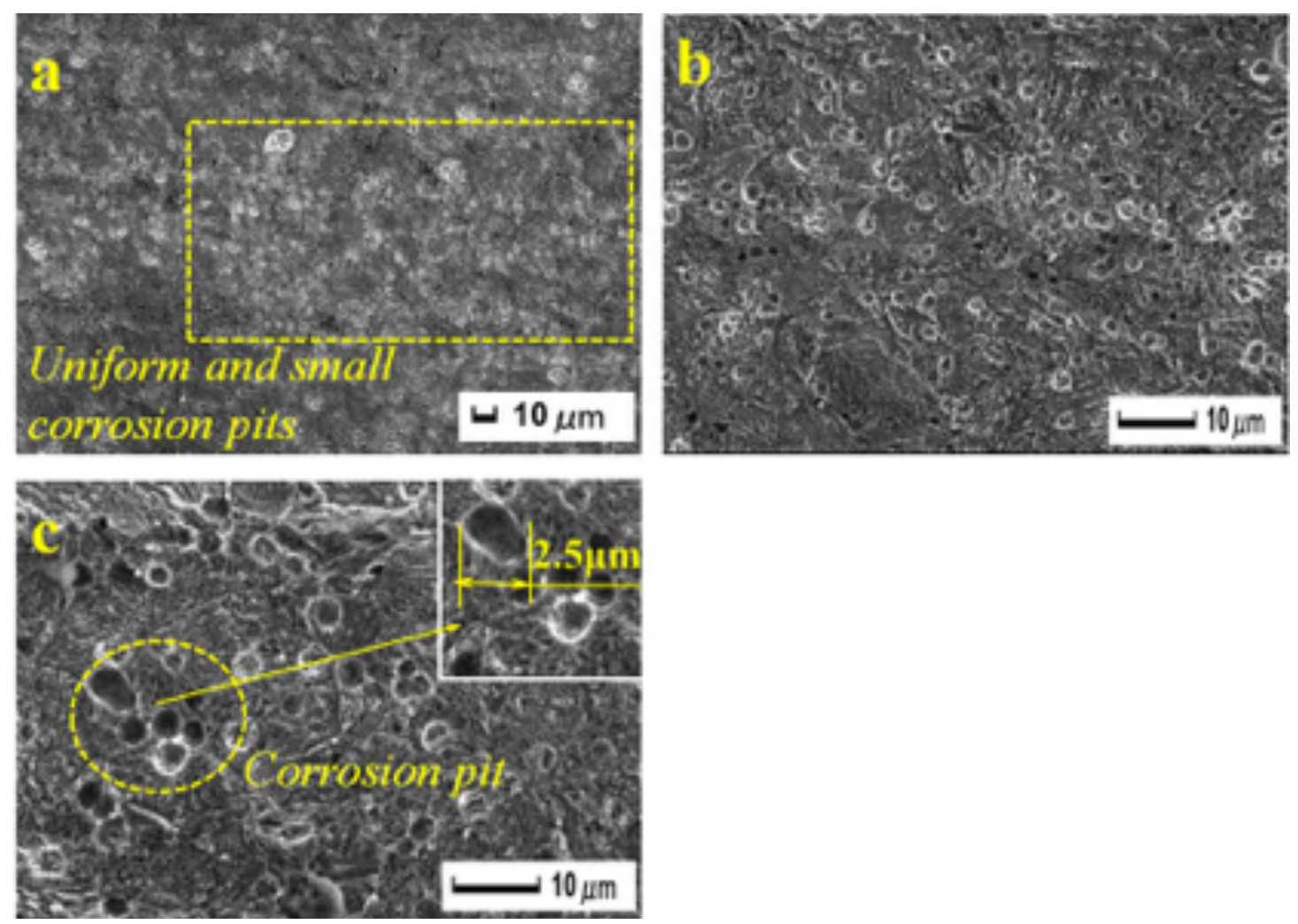

Fig. 10 Typical pitting morphologies of LSPed specimen with two coverage layers and a pulse of $8 \mathrm{~J}$ after electrochemical corrosion experiment. (a) uniform and small corrosion pits, (b) magnified pitting morphologies of uniform corrosion pits, and (c) typical corrosion pit with a size of $2.5 \mu \mathrm{m}$. 

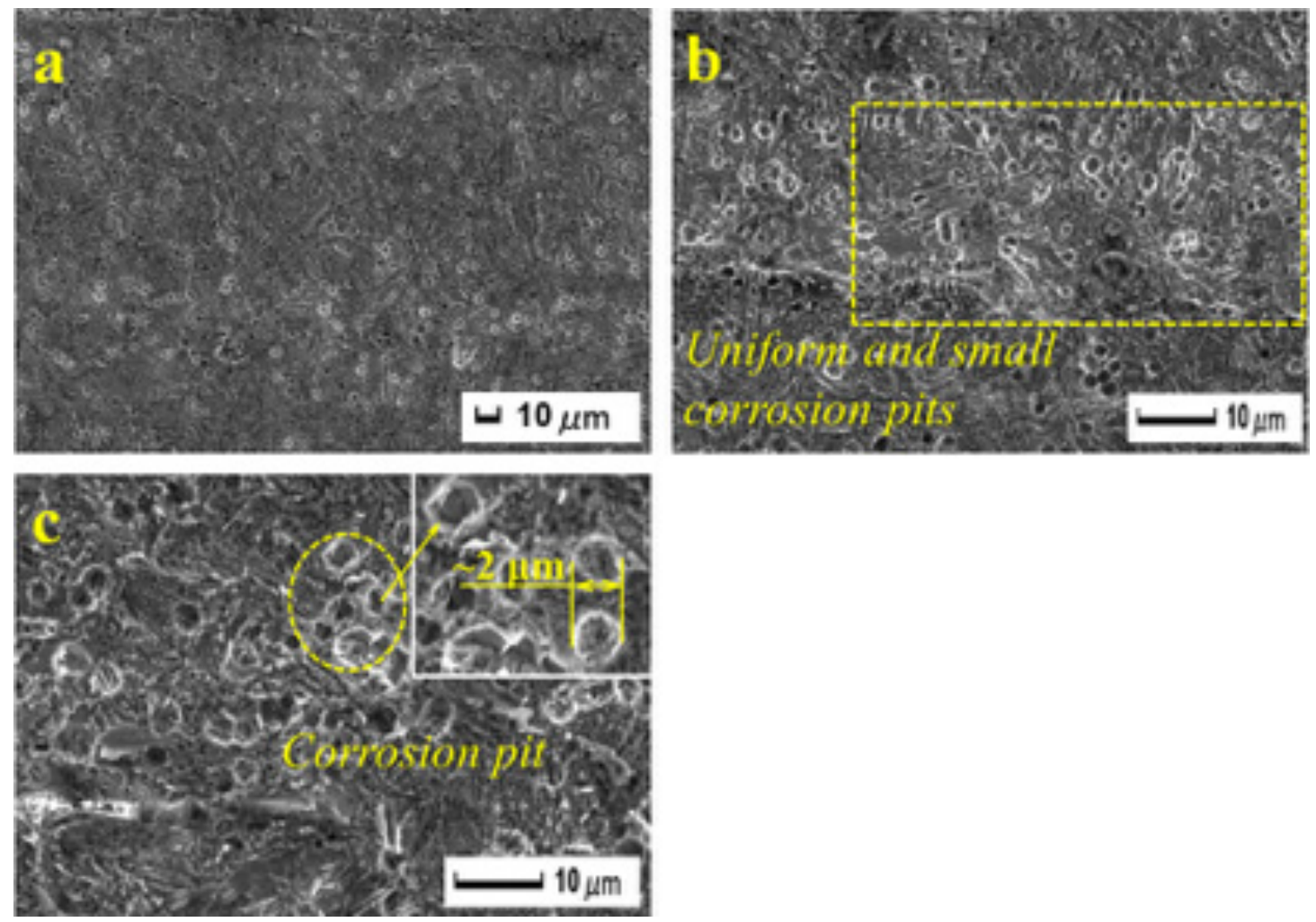

Fig. 11 Typical pitting morphologies of LSPed specimen with three coverage layers and a pulse of $8 \mathrm{~J}$ after electrochemical corrosion experiment. (a) whole pitting corrosion surface, (b) magnified uniform and small corrosion pits, and (c) typical corrosion pit with a size of $2 \mu \mathrm{m}$. 


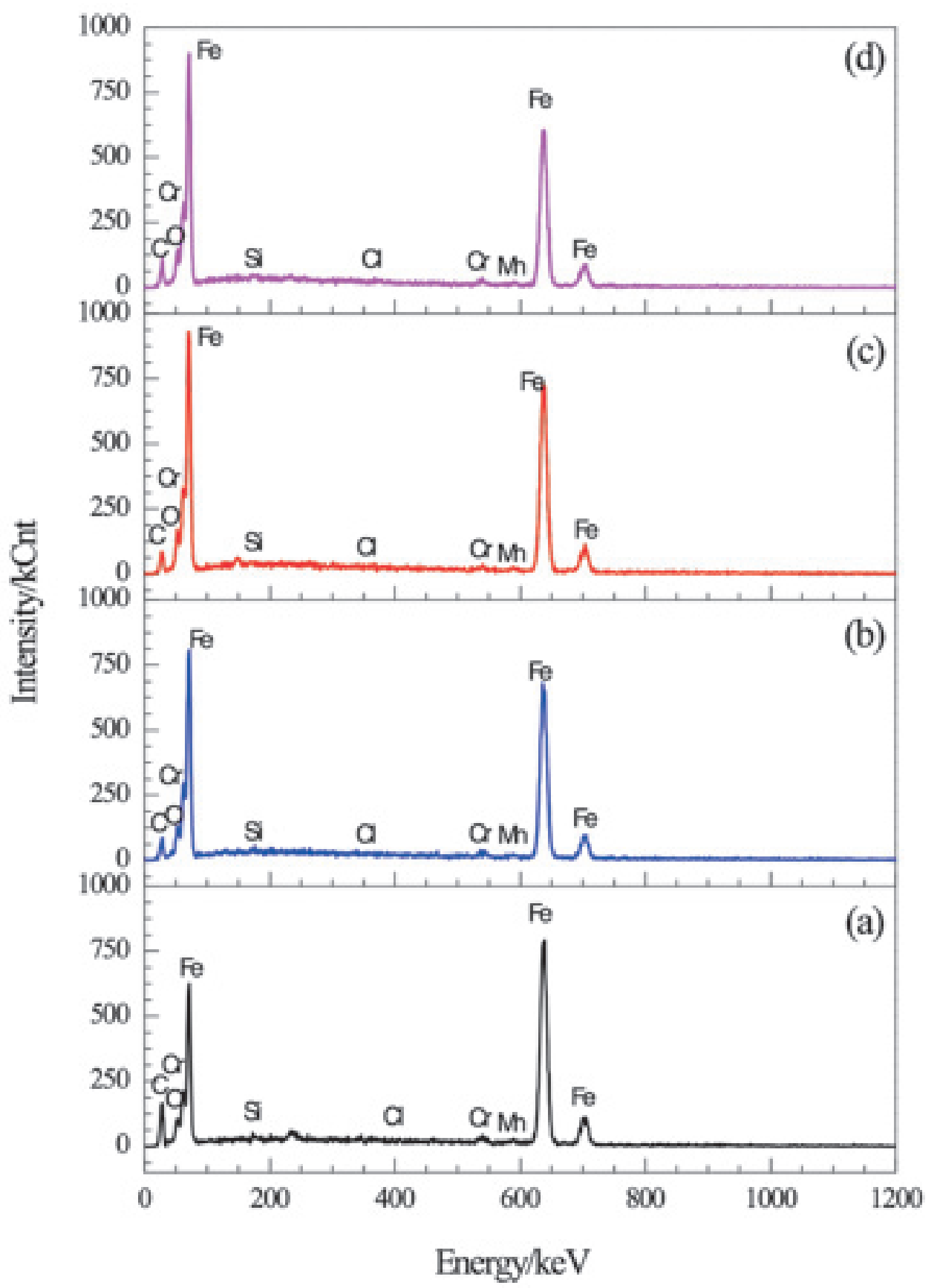

Fig. 12 Energy spectrums of four types of specimens after electrochemical corrosion testing. (a) as-machined specimen, (b) with one coverage layer and a pulse of $8 \mathrm{~J}$, (c) with two coverage layers and a pulse of $8 \mathrm{~J}$, and (d) with three coverage layers and a pulse of $8 \mathrm{~J}$. 

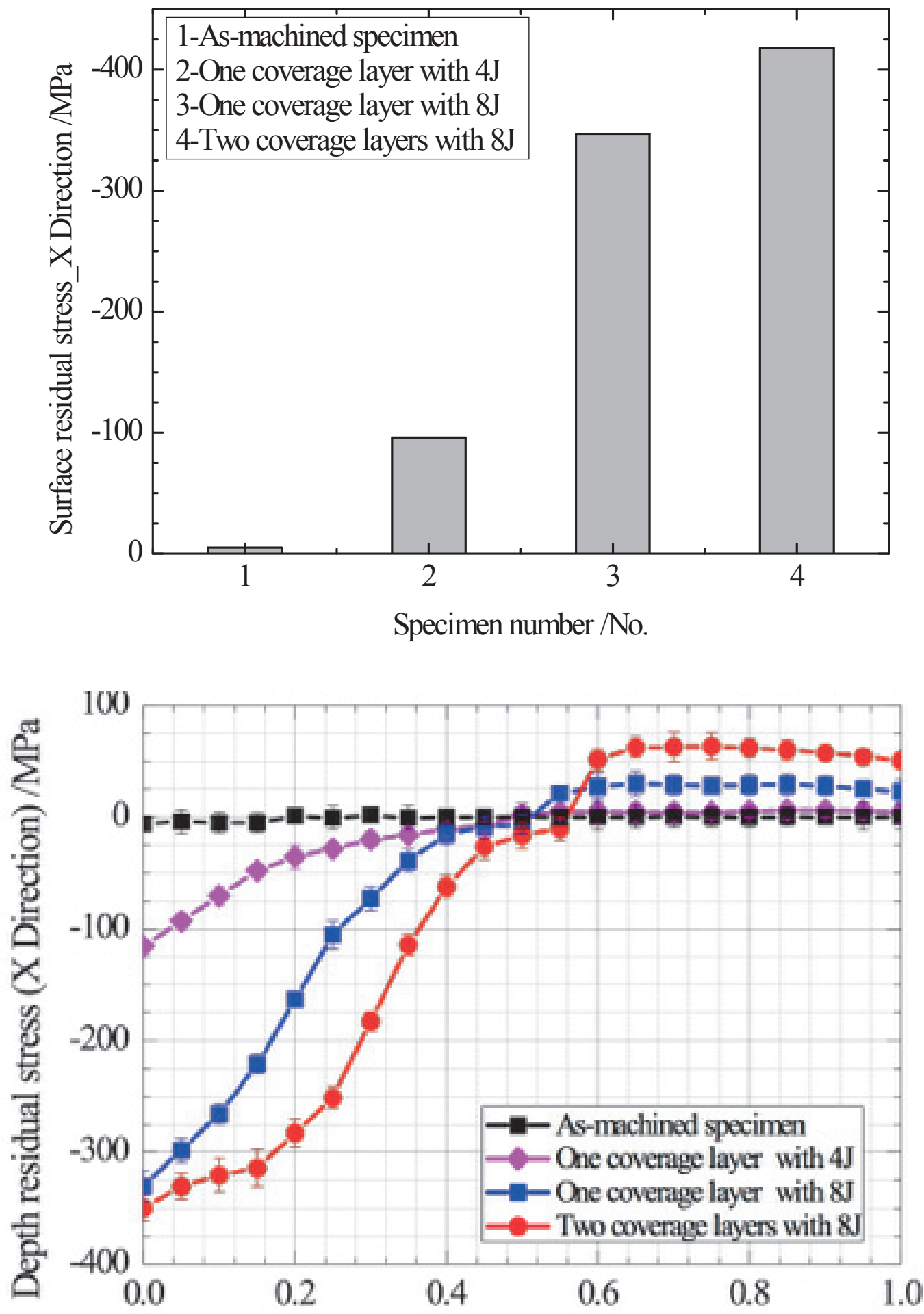

Distance from the top surface $/ \mathrm{mm}$

Fig. 13 (a) Surface and (b) in-depth residual stress distributions of as-machined specimen and three types of LSPed specimens. 

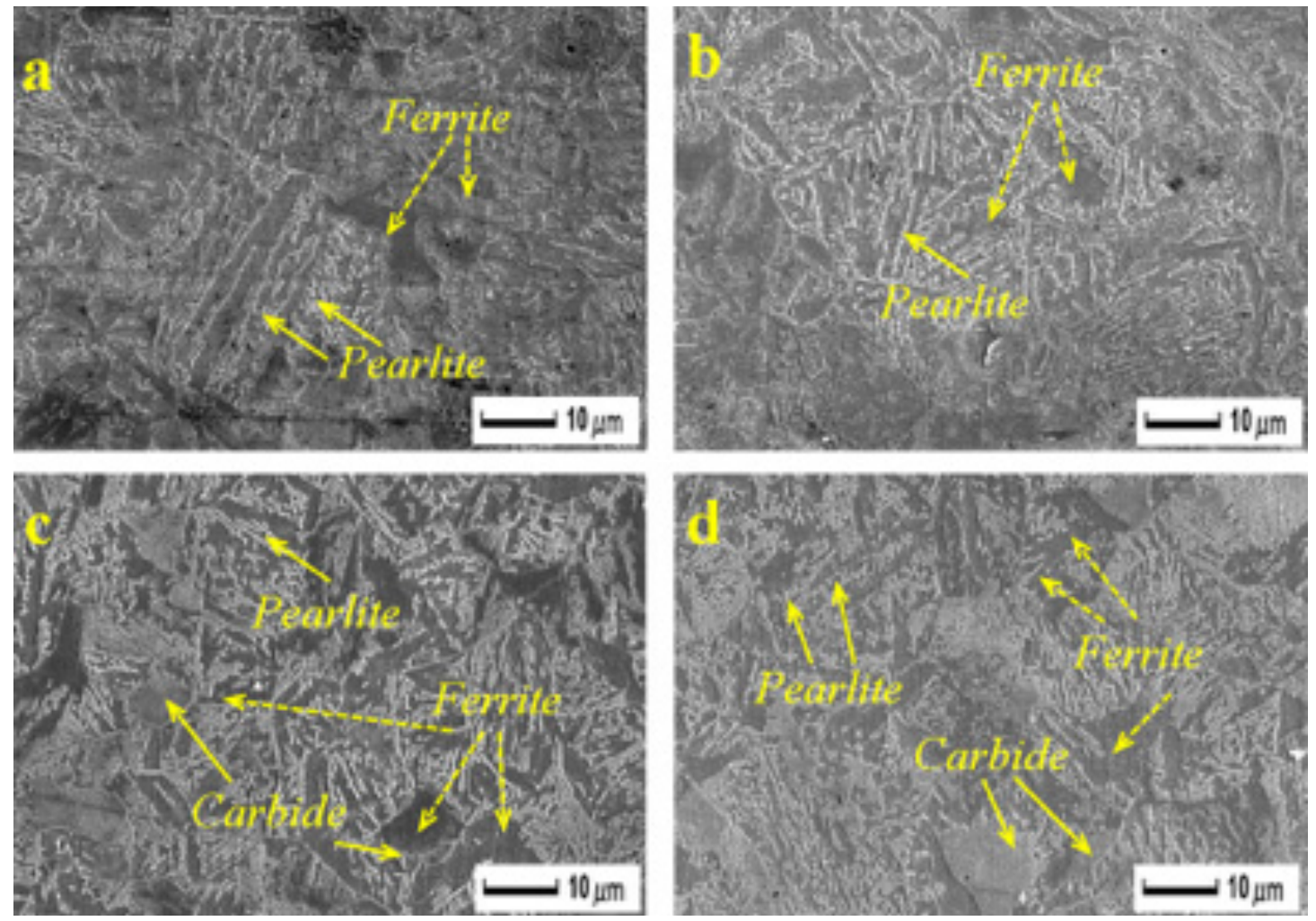

Fig. 14 Typical cross-sectional morphologies in the near surface layer of asmachined and three types of LSPed specimens immersed in the professional etching reagent for $5 \mathrm{~s}$ at room temperature. (a) as-machined specimen, (b) with one coverage layer and a pulse energy of $4 \mathrm{~J}$, (c) with one coverage layer and a pulse energy of $8 \mathrm{~J}$, and (d) with two coverage layers and a pulse energy of $8 \mathrm{~J}$. 
- Surface residual stress with $\sim-5 \mathrm{MPa}$

- Linear peerlite or strip-like pearlite, end the content of pearlite is obviously less than that of ferrite

- Non-uniform corrosion pits with about 20.35 um and a certain depth

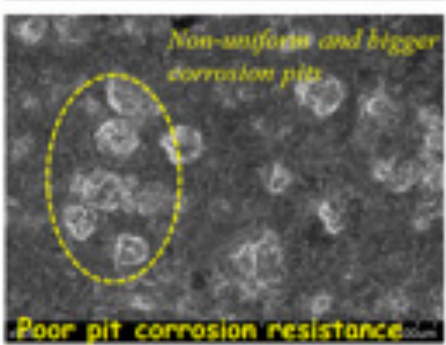

(a) As-machined specimen
- Surface residual stress with $=347 \mathrm{MPa}$

- Sheet-like pearlite with a large area and blecky carbides

Uniform corrosion pits with *2.5 um

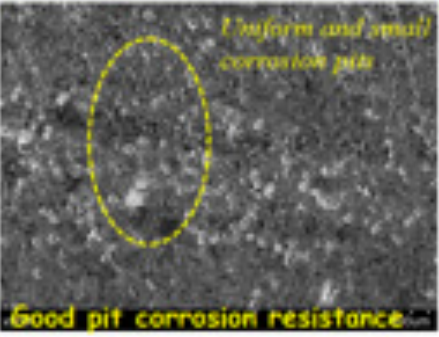

(b) L.SPed specimen with cese coverage layer

After massive LSP treatment with different coverage layers

Fig. 15 Schematic diagram of coverage layer during massive LSP treatment on pitting corrosion resistance of AISI 4145 steel. (a) as-machined specimen, (b) LSPed specimen with one coverage layer, and (c) LSPed specimen with multiple coverage layers. 
Table 1 Mechanical properties of AISI 4145 steel, including density, Poisson's ratio, elastic modulus, Hugonoit elastic limit, ultimate tensile strength, and dynamic yielding strength.

\begin{tabular}{ll}
\hline Mechanical property & Value \\
\hline Density, $\rho / \mathrm{kg} \mathrm{m}^{-3}$ & 7,850 \\
Poisson's ratio, $v$ & 0.28 \\
Elastic modulus, $E / \mathrm{GPa}$ & 212 \\
Hugonoit elastic limit, $H E L / \mathrm{GPa}$ & 2.5 \\
Ultimate tensile strength, $\sigma_{b} / \mathrm{GPa}$ & 1.125 \\
Dynamic yielding strength, $\sigma_{y}^{d y n} / \mathrm{GPa}$ & 0.985 \\
\hline
\end{tabular}


Table 2 Potentiodynamic polarisation test results of the as-machined specimen and LSPed specimens with different coverage layers in 0.598 mol/L NaCl solution at room temperature, and the electrochemical parameters and the corresponding errors: corrosion potential, corrosion current density, pitting potential, passive potential range, passive potential, and passive current density.

\begin{tabular}{|c|c|c|c|c|c|c|c|c|c|c|}
\hline $\begin{array}{l}\text { Coverage } \\
\text { layer }\end{array}$ & $\begin{array}{c}\text { Corrosion } \\
\text { potential } \\
\left(\mathrm{V}_{\mathrm{SCE}}\right)\end{array}$ & $\begin{array}{l}\text { Error } \\
\left(\mathrm{V}_{\mathrm{SCE}}\right)\end{array}$ & $\begin{array}{l}\text { Corrosion } \\
\text { current density } \\
\left(\mu \mathrm{A} / \mathrm{cm}^{2}\right)\end{array}$ & $\begin{array}{c}\text { Pitting } \\
\text { potential } \\
\left(\mathrm{V}_{\mathrm{SCE}}\right)\end{array}$ & $\begin{array}{c}\text { Error } \\
\left(\mathrm{V}_{\mathrm{SCE}}\right)\end{array}$ & $\begin{array}{c}\text { Passive } \\
\text { potential } \\
\text { range } \\
\left(\mathrm{V}_{\mathrm{SCE}}\right)\end{array}$ & $\begin{array}{l}\text { Error } \\
\left(\mathrm{V}_{\mathrm{SCE}}\right)\end{array}$ & $\begin{array}{c}\text { Passive } \\
\text { potential } \\
\left(\mathrm{V}_{\mathrm{SCE}}\right)\end{array}$ & $\begin{array}{l}\text { Error } \\
\left(\mathrm{V}_{\mathrm{SCE}}\right)\end{array}$ & $\begin{array}{l}\text { Passive current } \\
\text { density }\left(\mu \mathrm{A} / \mathrm{cm}^{2}\right)\end{array}$ \\
\hline $8 \mathrm{~J}-1$ & -1.06 & \pm 0.01 & 0.028 & -0.40 & \pm 0.03 & 0.65 & \pm 0.01 & -0.92 & \pm 0.01 & 50.12 \\
\hline $8 \mathrm{~J}-3$ & -0.99 & \pm 0.01 & 0.001 & -0.37 & \pm 0.02 & 0.62 & \pm 0.01 & -0.82 & \pm 0.02 & 0.60 \\
\hline
\end{tabular}


Surface residual stress with $\sim-5 \mathrm{MPa}$

- Linear pearlite or strip-like pearlite, and the content of pearlite is obviously less than that of ferrite

Non-uniform corrosion pits with about 20-35 $\mu \mathrm{m}$ and a certain depth

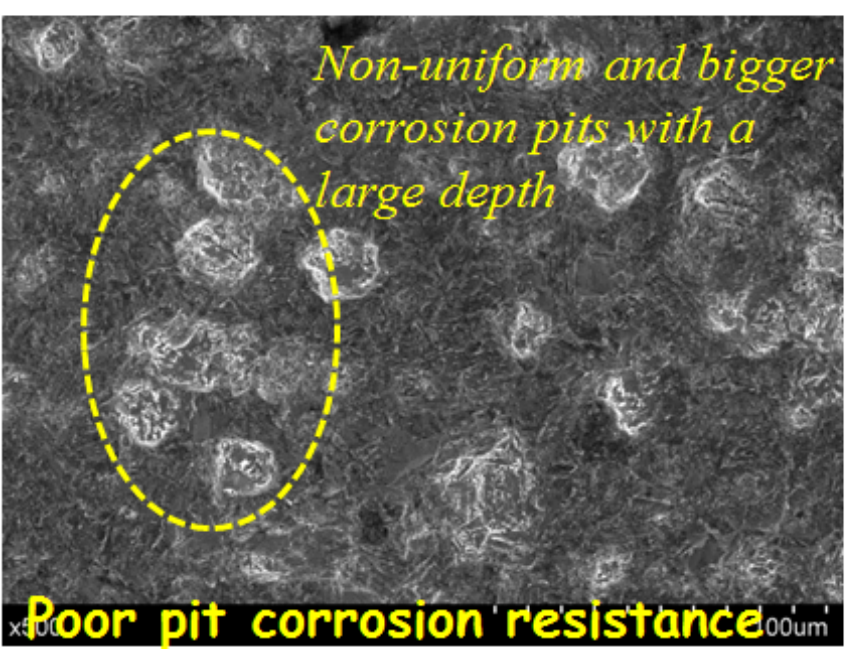

(a) As-machined specimen
Surface residual stress with $\sim-347 \mathrm{MPa}$

- Sheet-like pearlite with a large acreage and blocky carbides

- Uniform corrosion pits with $\sim 2.5 \mu \mathrm{m}$

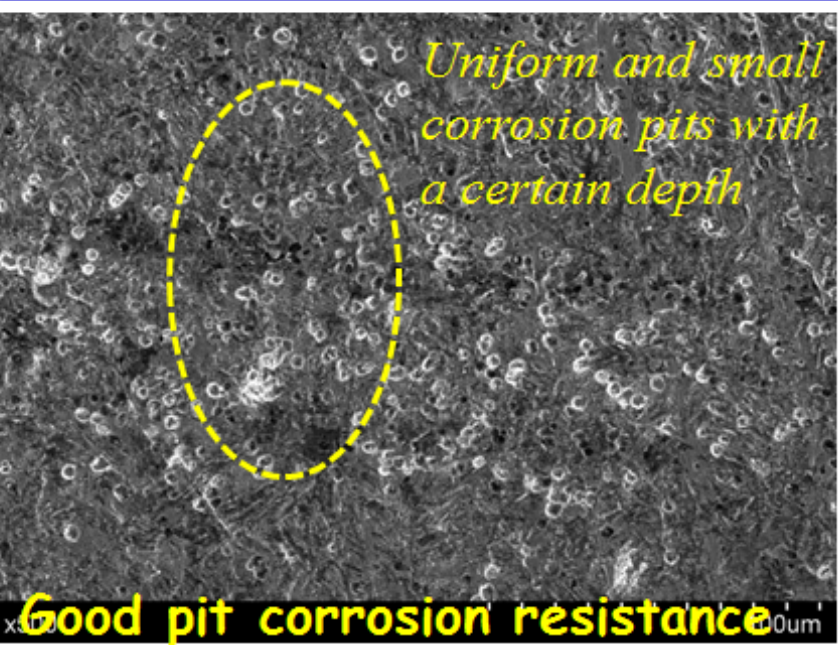

(b) LSPed specimen with one coverage layer

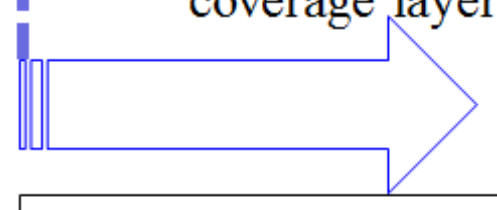

After massive LSP treatment with different coverage layers

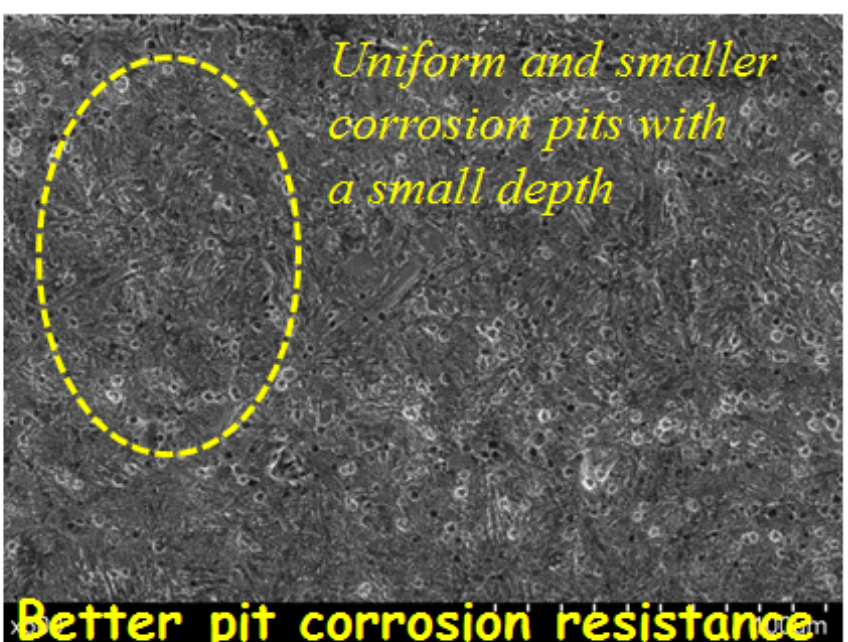

(c) LSPed specimen with multiple coverage layers

Surface residual stress with $\sim-418 \mathrm{MPa}$

- Strip-like pearlite and big blocky carbides at the majority of across-section

- Uniform corrosion pits with $\sim 2 \mu \mathrm{m}$ 